\title{
An In-depth Case Study of Selected WWTF Impacts
}

\author{
Grit LAUDEL
}

Technical University Berlin, Institute of Sociology

\section{$\mathrm{W}|\mathrm{W}| \mathrm{T} \mid \mathrm{F}$}
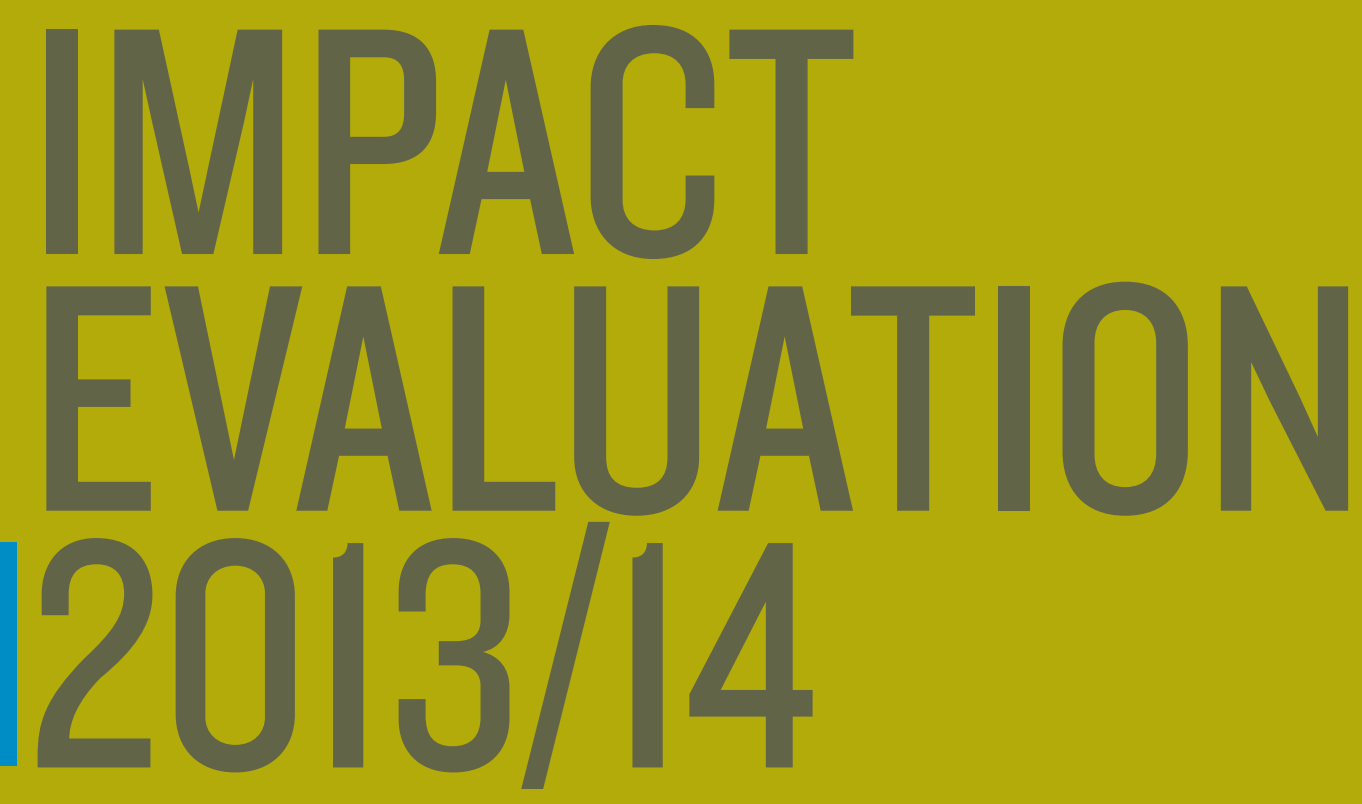


\section{Imprint}

Wiener Wissenschafts-, Forschungs- und Technologiefonds WWTF Vienna Science and Technology Fund

Schlickgasse 3/12, 1090 Wien/Vienna, Austria

T: +43 (O) 14023143

@office@wwtf.at

http://www.wwtf.at

(c) WWTF \& Grit Laudel 2013, Layout: WWTF

Author: Dr. Grit Laudel

Technical University Berlin, Institute of Sociology

Contact: grit.laudel@tu-berlin.de 


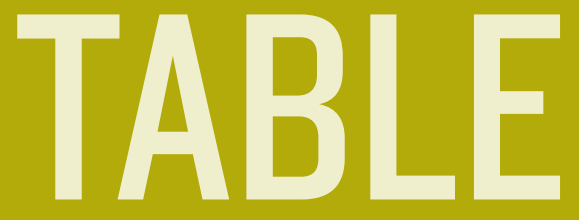

OF

CONTENT

\section{Executive Summary}

Deutsche Zusammenfassung

1. Introduction

2. Methodology

3. Characteristics of the investigated funding programs

4. The impact of WWTF funding on individual research portfolios

5. Does WWTF funding have an impact on the recipients' careers?
$5 \quad 6 . \quad$ Impact of WWTF funding on the Viennese research landscape

7. The WWTF in the ensemble of actors shaping the Viennese research landscape

8. Conclusions

References 43

Appendix 



\section{Aim of the study}

This study was commissioned by the WWTF as a contribution to the current evaluation of the WWTF's first ten years of funding activities. The WWTF aims at supporting interdisciplinary research, the establishment of critical masses in certain research areas as well as establish new research areas, and research with mid-term social benefits. The aim of this study was to investigate the impact of selected funding programmes of the Vienna Science and Technology Fund (WWTF) on (a) individual research portfolios of single researchers, (b) academic careers and (c) the Viennese research landscape.

A total of 25 researchers were investigated who received grants in the funding schemes "Project funding", "WWTF Science Chairs", "Vienna Research Groups for Young Investigators" in the research areas Life Sciences, Information and Communication Technology as well as Mathematics.

\section{Impact on individual research portfolios}

2.1 WWTF funding supported the continuation and broadening of existing research but also the start of completely new lines of research. It promoted risky research and research that deviated from the mainstream as well as 'business as usual'. Interviewees commented that the WWTFs attitude to risky research is unusual in the Austrian context.

2.2 The expectation of the WWTF that a project should have mid-term to long-term social benefits was applied through the design of specific calls such as "Linking Research and Patients' Needs". In the decision process on applications, the criterion was applied flexibly enough to enable support for a variety of links between basic research and applications. A more rigid use of this criterion is not recommended because it might compromise other aims.
2.3 Specific calls were also used to promote interdisciplinary research. These calls coupled wide thematic expectations with the expectation that interdisciplinarity would be realised through collaboration. This combination let the calls make researchers think about new projects or to apply with projects they thought would not have had a chance of funding otherwise. Grantees found the approach of the WWTF very interesting, most notably in the "Mathematics and ..." programme.

2.4 The durability of changes in research is difficult to assess because the WWTF's funding acti-vities are too recent. Only the structural changes the WWTF initiated with two of its program-mes (the establishment of chairs in the fields of the WWTF's Science Chairs and the tenure-track positions for Vienna Research Group Leaders) can be assumed to persist at this point in time. While several researchers reported that they used WWTF funding for initiating new lines of research or at least new projects, the continuation of this research depends on the interviewees' future research interests, careers, and successful acquisition of external funding.

\section{Impact on academic careers}

3.1 WWTF grants directly shaped a career phase by providing a salaried position for some applicants, namely fixed-term professorships, tenure-track positions, and in some cases fixed-term positions for recipients of project grants. They also initiated international mobility because they attracted researchers from abroad. WWTF grants supported some early career researchers in their transition to full independence because they provided autonomous discretion over resources for the first time in their careers.

3.2 An indirect effect on all careers can be expected from the symbolic or material value of the grant, which enhanced the reputation of grantees and thus their chances in subsequent recruitment processes. However, this indirect effect is overlaid by many other factors and therefore the WWTF's contribution is difficult to assess. 
3.3 The effects of WWTF funding are likely to last for the Science Chairs, who were appointed to permanent full professorships after the end of their WWTF-funded term. While it is difficult to tell what the effects for VRG Leaders will be because none of them has finished their term, some doubts can be raised. VRG Leaders will get permanent positions but will receive very little recurrent funding beyond their salaries. If the WWTF made the right decision in funding them, they are likely to receive much more attractive offers from abroad once their time as VRG Leaders ends. The same applies to recipients of project grants, at least in principle.

\section{Impact on the Viennese research landscape}

Within the limits of this study, some mechanisms through which WWTF funding contributes to shaping the Viennese research landscape could be identified:

- The WWTF's selection procedure for Science Chairs and VRG Leaders strongly involves the universities. This way, the WWTF achieves a very good fit of candidates with the local research environment of the university and, by extension, with the Viennese research landscape. This fit manifested itself either as a strengthening of existing fields, which always coincided with the addition of a new area of expertise, or as the filling of gaps in the research landscape.

- The new research of WWTF grantees also created new demand for interdisciplinary collaboration, thereby revealing further gaps in the Viennese landscape.

\section{The WWTF in the ensemble of research actors}

The WWTF is only one of the organisations that together shape the Viennese research landscape. It increased its influence by requiring a commitment by the host organisations for Science Chairs and VRG Leaders, which has already proved to be successful for Science Chairs. This approach still awaits its test for VRG leaders, particularly because the WWTF cannot influence their future research base.

The WWTF also supplemented other organisations by providing research funding for female researchers on fellowships, meeting above-average resource needs, and fostering risky research.

\section{General remarks}

Judging from the interviews with grantees, the WWTF has managed to achieve its aims by following a creative strategy that does not attempt to mirror what other major funding agencies in Austria do. It concentrates its resources in order to provide above-average funding for the few projects it can fund within the limits of its budget, and leverages more investment. The promotion of collaboration, both interdisciplinary and between basic and applied research, was beneficial to most of the investigated projects. While a selective funding strategy like the WWTF's is only possible for funding agencies that don't have the task of providing funding for everyone, it is still remarkable, even by international comparison.

Unfortunately, the most serious limitations to the WWTF's funding strategy appear to be outside its control. The WWTF provides generous funding that enables interesting research but does so only for a fixed term. Several interviewees were concerned about keeping up this level of funding. The situation appears to be particularly grave for the VRG Leaders, who face the prospect of being on a permanent position but having to apply for everything else. There is little danger that former WWTF grantees move to other Austrian universities because they won't find better funding opportunities there. However, keeping the researchers the WWTF managed to attract to Vienna in Austria might turn into a problem. 


\section{DEUTSCHE ZUSAMMENFASSUNG}

Die vorliegende Studie entstand anlässlich der Evaluierung der zehnjährigen Tätigkeit des Wiener Wissenschafts-, Forschungs- und Technologiefonds (WWTF). Der WWTF hat den Auftrag, die Wiener Forschungslandschaft in ausgewählten Bereichen durch gezielte Projekt- und Personenförderung zu stärken. Er unterstützt vor allem interdisziplinäre Forschung und solche mit einer mittelfristigen Anwendungsperspektive.

Ziel der Studie war es, Effekte der WWTF-Förderung auf die Forschungen und akademische Karrieren der Geförderten sowie auf die Wiener Forschungslandschaft zu identifizieren. Ihre Grundlagen bilden 25 Tiefeninterviews mit durch den WWTF finanzierten Wissenschaftlerlnnen, die auf den Gebieten Lebenswissenschaften, Informations- und Kommunikationstechnologie und Mathematik tätig sind. Obwohl sich noch nicht alle Wirkungen der WWTF-Förderung entfalten konnten, da die ersten geförderten Projekte erst vor kurzem abgeschlossen wurden, ließen sich bereits wichtige Effekte beobachten.

\section{Wie wirkte sich die Förderung auf die For- schungen von Wiener WissenschaftlerInnen aus?}

In vielen Fachgebieten sind WissenschaftlerInnen heute in ihrer Forschung auf Drittmittel angewiesen, da die universitäre Grundausstattung für die Finanzierung von Forschung nicht ausreicht. Förderorganisationen wie der WWTF haben deshalb - abhängig von ihrem Finanzierungsvolumen - entscheidenden Einfluss darauf, wer welche Forschungen durchführen kann. Der WWTF hat diesen Einfluss genutzt, um

- Forschungen zu fördern, die trotz ihrer Qualität anderenfalls nur schwer eine Förderung gefunden hätte (zum Beispiel weil sie riskant ist oder dem Mainstream widerspricht)

- Forschungen anzuregen, die eine wichtige Ergänzung für die Wiener Forschungslandschaft bedeuten, und

- Exzellente Wissenschaftlerlnnen nach Wien zu holen.
Der WWTF hat eine Lücke in der österreichischen Förderlandschaft gefüllt, indem er riskante Forschungen und Forschungen, die vom Mainstream abweichen, bevorzugt förderte.

Forschungen mit einer mittelfristigen Anwendungsperspektive sind durch spezifische Förderprogramme wie „Linking Research and Patients' Needs" gefördert worden. Diese Programme waren erfolgreich, da der WWTF nicht dem generellen politischen Trend folgte und einen baldigen Nutzen forderte oder die bereits starke existierende Förderung von industriegebundener Forschung kopierte, sondern das Kriterium „Anwendungsperspektive" flexibel und den Spezifika der Fächer entsprechend anwendete, was zu interessanten neuen Themen führte. Spezifische Programme sind auch auf die Förderung interdisziplinärer Kooperation in für die Wiener Forschungslandschaft wichtigen thematischen Schwerpunkten gerichtet. Die Orientierung der Förderprogramme auf ungewöhnliche Fächerkombinationen hat Wiener WissenschafterInnnen angeregt, neue Themen und Themen, für die sie sonst schwerlich eine Finanzierung bekommen hätten, zu bearbeiten. Vor allem das Programm "Mathematics and ..." war hier sehr erfolgreich.

Ob Wissenschaftlerlnnen die durch den WWTF angestoßenen neuen Themen dauerhaft weiter bearbeiten können, ist noch offen, da die WWTF-Förderung noch zu jung ist. Es ist jedoch sehr wahrscheinlich, dass insbesondere die durch Förderung von Stiftungsprofessuren und ForschungsgruppenleiterInnen angestoßenen neuen Themen fortgesetzt werden. Ob andere Forschungen fortgesetzt werden können, hängt von Karrieremöglichkeiten, zukünftigen Forschungsinteressen und dem Zugang zu Drittmitteln ab, Bedingungen, auf die der WWTF kaum beeinflussen kann.

\section{Welche Wirkungen hatte die Förderung auf akademische Karrieren?}

Der WWTF beeinflusste Karrieren, in dem er Stellen für Antragstellerlnnen bereitstellt: befristete Professuren, 
Tenure-track-Stellen und mitunter befristetet Projektleiterstellen. Internationale Mobilität wurde gefördert, indem es gelang. WissenschaftlerInnen aus dem Ausland anzuziehen (Bewerberlnnen für Stiftungsprofessuren und Wiener Forschungsgruppenleiterstellen müssen aus dem Ausland kommen).

Der WWTF fördert insbesondere NachwuchswissenschaftlerInnen. Indem er sie mit Ressourcen ausstattete, konnte ein Teil von ihnen eigene, selbständige Forschungslinien aufbauen - ein wichtiger Schritt für die weitere Karriere.

Karriereeffekte sind am ehesten dauerhaft für Stiftungsprofessoren, insbesondere diejenigen, die inzwischen erfolgreich auf Universitätsprofessuren berufen worden sind. Für die Wiener GruppenleiterInnen ist es schwer vorherzusagen, ob sie in Zukunft Dauerstellen (Assoziierte Professuren) in Wien annehmen wollen, trotz der Tenure-Option, die mit der WWTF-Förderung kommt. Es liegen noch keine Erfahrungen vor, weil das Programm erst seit 2010 existiert. Da die Assistenzprofessuren nach der WWTF-Förderperiode außer der eigenen Stelle keine weiteren Forschungsmittel vorsehen, ist zu befürchten, dass die GruppenleiterInnen attraktivere Angebote aus dem Ausland bekommen (zumindest in ressourcenintensiven Fächern). Solche Situationen traten auch bei WWTF geförderten ProjektleiterInnen auf, die inzwischen attraktive Angebote im Ausland erhielten.

\section{Welche Wirkungen hatte die Förderung auf die Wiener Forschungslandschaft?}

Der WWTF hat Förderprogramme aufgelegt, die exzellente WissenschaftlerInnen aus dem Ausland nach Wien bringen. Bei der Auswahl von Stiftungsprofessoren und LeiterInnen von Wiener Forschungsgruppen bezieht der WWTF die Wiener Universitäten stark ein. Auf diese Weise wird erreicht, dass die Kandidaten sehr gut in die lokale Forschungsumgebung und in die Wiener Forschungslandschaft passen. Dadurch wurden für die Wie- ner Forschungslandschaft wichtige Gebiete gestärkt. In anderen Fällen gelang es dem WWTF, Lücken in für Wien wichtigen Fachgebieten zu füllen (insbesondere mit dem Instrument der Stiftungsprofessur). Zugleich hat die Forschung der vom WWTF Geförderten auch Lücken im Sinne möglicher Synergien aufgedeckt, indem Bedürfnisse nach neuen interdisziplinären Kooperationen entstanden sind.

\section{Fazit}

Der WWTF hat seine Ziele durch ein kreatives Herangehen erreicht: er hat nicht versucht, das zu kopieren, was andere große Förderorganisation wie der FWF (Fonds zur Förderung der wissenschaftlichen Forschung) schon tun. Anders als andere Förderorganisationen hat der WWTF nicht die Aufgabe, Forschungsfinanzierung für alle bereitzustellen, sondern er kann selektiv sein. Wie diese selektive Förderung realisiert wird, ist - selbst im internationalen Vergleich - bemerkenswert.

Die größte Limitierung der WWTF-Förderung ist ihre Endlichkeit: Projekte werden für drei, vier, oder fünf Jahre gefördert. Der WWTF hat häufig keinen Einfluss auf die Verstetigung der von ihm angestoßenen Forschungen. Geförderte WissenschaftlerInnen (insbesondere Wiener Forschungsgruppenleiterlnnen) befürchteten, dass die Weiterfinanzierung der einmal aufgebauten Forschung schwierig wird. Damit besteht die Gefahr, dass Wien zumindest einen Teil der durch den WWTF angezogenen Wissenschaftlerlnnen wieder verliert.

Mit den geringen Mittel, die ihm zur Verfügung stehen, konzentriert der WWTF seine Ressourcen auf die Förderung gut finanzierter Projekte für exzellente WissenschaftlerInnen und mobilisiert zusätzliche Mittel der Forschungsorganisationen. Die Förderung von Kooperationen - sowohl interdisziplinäre als auch zwischen grundlagenorientierter und anwendungsorientierten Gruppen war für die meisten der hier untersuchten Projekte nützlich. 


\section{INTRODUCTION}

For the unfamiliar reader let us briefly introduce the Vienna Science and Technology Fund (Wiener Wissenschafts-, Forschungs- und Technologiefonds, WWTF). The WWTF is a local research funding agency that was established in 2001. Its mission is the promotion of research in Vienna by contributing to the accumulation of critical mass of excellent research in selected fields (WWTF 2008a). The WWTF is a private, non-profit organisation. Since funding of research commenced in 2003, its total annual budget for research funding has varied between five and eleven million Euros.

With its funding instruments the WWTF targets specific research areas, for which it issues thematic calls for proposals. The current funding priorities target

- the life sciences (since 2003);

- interdisciplinary approaches of mathematics (since 2004);

- information and communication technologies (since 2008); and

- cognitive science (since 2009).

The WWTF has a portfolio of instruments for research funding in these thematic areas, which include project funding (for which early career researchers have been particularly encouraged to apply), research groups for young scientists, and fixed-term professorships ("Science Chairs"). In addition to its own funding programmes, the WWTF administers since 2008 a programme in the Social Science and Humanities and a funding programme for university infrastructure, which are both financed by the city of Vienna.

The empirical study whose results are reported here is a contribution to the evaluation of the WWTF, which has been initiated by the WWTF Board of Directors to assess the impacts of the first ten years of funding activities. The aim of the present study is to investigate the impact of selected WWTF funding programmes on

(a) individual research portfolios,

(b) academic careers (of male and female scientists), and

(c) the Viennese research landscape.

The main object of the study are researchers who received WWTF funding, particularly Principal Investigators. Among them, a special emphasis is put on early career researchers and their research portfolios and career paths.

This study was commissioned by the WWTF, which also supported it over the last five months. I am grateful to Michael Stampfer and Michael Strassnig from the WWTF office who assisted me by providing access to documents, context information about the WWTF and its regulations, and administrative support during my stay in Vienna for the interviews with researchers. Except for the selection of funding programmes to be covered by my study, the WWTF did not influence its content (see the section on methods).

A study like this is only possible with the support of the grantees. The grantees who agreed to be interviewed shared with me the most precious resource a researcher has, namely their time. Altogether, it amounted to 35 tape-recorded hours of interviews. I am very grateful for this time and for my interviewees' patience when they had to explain their research to me. 



\section{2. methodology}

The general methodology for this project had been developed, tested and applied in previous projects, particularly in a study on the impact of European Research Council funding on the grantees' careers and research lines (Laudel and Gläser 2012).

\section{I Research Strategy}

Impact is defined here as attributable change. The challenge of a qualitative study of impact is to causally attribute changes in grantees' research content or careers and in the Viennese research landscape to the WWTF funding schemes. This is achieved here by an in-depth study of the use of WWTF funding by grantees. The comparative case studies systematically vary major intervening variables, namely field, career stage, and gender.

Since individual researchers are recipients of funding, they were considered to constitute the cases of changes in research and careers. Their research history, research conditions, and careers were studied.

The attribution of change was hindered by conditions beyond the control of the study (or, for that matter, the WWTF). In particular, most of the change initiated by funding can be expected after the funded projects are finished, which is not yet the case for any of the VRG Leader projects. Many projects from other funding programmes have been finished very recently, which also hampers the impact assessment. Within these limits, change can be attributed to the WWTF if it occurs because

- a WWTF application was written or a project was funded by the WWTF; and

- the application or the funding of the project led to decisions by the grantee which resulted in the observed change.
These links were explored by extensive discussions of the interviewees' research, its resource requirements, and the contribution of the WWTF to meeting these requirements. This analysis follows the tradition of a 'mechanismic' approach by establishing how the change achieved through the WWTF grants is brought about. If furthermore

- no alternative funding schemes exist that could have produced a similar change, and

- if properties of the grantee's national research system can be identified that make such a change unlikely without the special support of the WWTF-type funding scheme:

then we can say that the change can be produced only by the WWTF funding scheme (the WWTF funding was a necessary condition for the change to occur). To fully assess the latter conditions would have required a full investigation of the Austrian funding system, which was impossible given the constraints for this study. However, alternatives to WWTF funding were discussed in the interviews.

\subsection{Case selection}

The case selection was shaped by considerations of suitability for the purpose of the evaluations, the interest of the WWTF in specific funding programmes, and the time constraints of the study. Only successful WWTF grantees were interviewed. While including non-applicants and unsuccessful applicants as 'control groups' was desirable, the limited number of interviews that could be conducted in the available time and the resulting tradeoff between the coverage of different funding schemes and the inclusion of control groups led to the decision to limit the cases to grantees. For the same reason, no in- 
terviews with managers of grantees' host organisations, which would have revealed organisational responses towards WWTF funding, could be included. Owing to time constraints - the study had to be completed in less than six months - the scope of the study was restricted to 25 cases of successful WWTF grantees.

The case selection should support the investigation of a large variety of situations in which WWTF funding is applied, and the impacts it has in these specific situations. The following criteria were applied in the selection of funding programmes to study:

1. Position of funding programmes in the strategy of the WWTF: Funding programmes to study were selected jointly by the WWTF and myself. Discontinued programmes or programmes that are likely to be discontinued in the near future were excluded. On the other hand, funding programmes that the WWTF designed to fill a specific gap in the external funding landscape were of particular interest. Additionally to project funding instruments of funding specific persons and their research programmes were included. These instruments directly target scientific careers and due to substantial funding amount per grant may also have structural effects on the Vienna research landscape.

2. Disciplines: From the disciplinary priorities of the WWTF, three disciplines were selected, namely life sciences, mathematics, and information and communication technologies. Table 1 gives an overview of the selected programmes and instruments. Grantees in these programmes were selected for interviews. The WWTF asked me to include all VRG Leaders, apart from the most recent two VRG Leaders who had not yet or only just started. In the selection of the other interviewees, the following criteria were applied
3. Variation of career position: Researchers from different career stages from early career to late career were included. Since the study is particularly interested in effects on the early career, early career researchers were selected more frequently than others. For the same reason, researchers funded under the scheme of Vienna Research Group Leaders were included.

4. Time since the WWTF project was granted: For an impact study it is crucial that sufficient time passed since the grant was awarded. Wherever there was a choice, projects that were finished for some time or at least projects that were close to be finished were included. This doesn't hold for researchers funded in the 'Vienna Group Leader' programme because the programme is too recent.

5. Variation of organisational position: Researchers on fixed-term positions (funded by the WWTF or by the research organisation) and permanent positions were included.

6. Variation of exclusiveness of research funding: researchers for whom the WWTF grant was the only source of external funding and researchers who simultaneously had other sources of external research funding were included.

7. Variation of fields: Within the three broader disciplinary areas, projects from different subfields were selected.

8. Variation of gender: male and female researchers from each discipline and funding programme were included where possible (there were no female Science Chairs).

\begin{tabular}{|l|c|c|c|}
\hline & \multicolumn{3}{|c|}{ Reasons for selecting the programme } \\
\hline $\begin{array}{l}\text { Funding programmes and inst- } \\
\text { ruments }\end{array}$ & Continuing programme & $\begin{array}{l}\text { WWTF strategic aim "filling a gap } \\
\text { in the funding landscape" }\end{array}$ & $\begin{array}{l}\text { WWTF strategic aim "targeting } \\
\text { careers and Viennese research } \\
\text { landscape" }\end{array}$ \\
\hline Project funding & $\times$ & & \\
\hline Life Sciences & $\times$ & & \\
\hline $\begin{array}{l}\text { Life Sciences/ Linking Re- } \\
\text { search and Patients' Needs }\end{array}$ & $\times$ & & \\
\hline $\begin{array}{l}\text { Information and Communica- } \\
\text { tion Technology }\end{array}$ & $\times$ & $\times$ & \\
\hline "Mathematics and ..." & $\times$ & $\times$ & \\
\hline Vienna Research Groups & $\times$ & $\times$ & $\times$ \\
\hline Science Chairs & $\times$ & $\times$ & \\
\hline
\end{tabular}


9. Variation of researcher quality and project success: To make sure that high quality research and researchers are included in the empirical study, the WWTF provided a list of 39 Principal Investigators "where the WWTF knows that the performance of these projects is above average based on reports, career steps and publications." (WWTF 2013) From this list I selected around half of the interviewees. ${ }^{1}$ The other interviewees were selected from a database of grantees provided by the WWTF according to the other eight criteria. Four WWTF funded projects were excluded from the study. According to the WWTF they present rather unusual cases of personal mismanagement at one institute that would be hard to access for an interview and even harder to interpret in terms of impact.

Of the 25 grantees that were selected for interviews eight were female. Ten interviewees were early career researchers when they received the grant, i.e. their PhD completion was less than five years ago. Table 2 shows the distribution of interviewees across funding instruments and disciplines. All selected grantees agreed to be interviewed. In one case, the principal investigator was unexpectedly unavailable, and instead two group members were interviewed.

\subsection{Methods}

Measuring change in the content of research in a way that uses the interview responses of researchers but goes beyond their opinion them is extremely difficult. It requires that the social researcher forms an opinion about changes in knowledge independently of the interviewee's opinions. In this project, I applied an interview technique and data analysis strategy that enable an independent assessment of structural and epistemic properties of the research. 'Independent' means that while interviewees' accounts of changes in their research are used in the analysis, they are not taken for granted and aggregated but are used as material for analysis from which conclusions are drawn. The basic idea underlying this approach is extensively discussing the content of interviewees' research during the interview and soliciting scientific narratives about the choice of problems, objects, methods, and collaborators. While the content of these narratives cannot be assessed by sociologists, we can reconstruct the logic of the interviewees' description and assessment of conditions of research as well as the logic of the decision-making by which interviewees responded to those conditions.

The interviews with researchers consist of two main parts (see appendix 1 for an example interview guide). In the first part the research funded by the grant is discussed in the context of the interviewee's previous, parallel and, if applicable, subsequent research projects. In this discussion, the continuity of research and all thematic changes as well as reasons for them are explored. The discussion is based on a bibliometric analysis of the interviewee's publications that enables the identification of thematically linked publications. A visualisation of this publication network is used to stimulate the recall and to prompt narratives about the content of research (Gläser and Laudel 2009). Figure 1 shows an example of such a visualisation of research trails.

The picture shows the interviewee's publications (circles) linked (lines) by bibliographical coupling (the relative number of references that occur in both publications' reference lists). These publications were downloaded from the Web of Science. The relative size of circles represents the number of citations received by the publication, which is interpreted here as the visibility of this publication to the interviewee's scientific community. Below the time axis, the interviewee's organisational positions are listed. The uppermost part of the picture contains names of projects as could be derived from available sources. In fields where the Web of Science

\begin{tabular}{|l|c|c|}
\hline & \multicolumn{2}{|c|}{ Number of cases } \\
\hline & Project funding & VRG Leaders and Science Chairs \\
\hline Life Sciences & 2 & 5 \\
\hline $\begin{array}{l}\text { Life Sciences/ Linking Research and Patients' } \\
\text { Needs }\end{array}$ & 3 & - \\
\hline "Mathematics and ..." & 7 & 1 \\
\hline Information and Communication Technology & \multicolumn{1}{|c|}{25} \\
\hline \multicolumn{2}{|c|}{ Total } & \multicolumn{2}{|c|}{2} \\
\hline
\end{tabular}


only provides a poor coverage (e.g. in some fields of ICT or Mathematics), the pictures were produced on the basis of publication lists from interviewees' CVs. Title keywords are used for identifying thematically connected publications.

The resulting pictures were used in the beginning for a reconstruction of the interviewee's research biography. A specific line of questioning focused on the research funded by the WWTF grant. The relationship between the WWTF project and previous research was explored. The discussion of content requires a scientific preparation by the interviewer at an 'advanced layperson's' level and the negotiation of a level of communication at the beginning of the interview (Laudel and Gläser 2007). For this preparation, internet searches, publications at various levels of difficulty (from popular science up to an interviewee's publications) and the WWTF grant proposals, referee reports, and project reports were used.

In a second part of the interview, research conditions and the factors influencing them were discussed. This separation of research content and research conditions is crucial because it limits the extent to which interviewees present their own subjective theories and opinions about the impact of WWTF grants.

The interviews lasted on average 80 minutes. They were recorded, fully transcribed, and analysed with qualitative content analysis (Gläser and Laudel 2013). Sorting the information according to different targets and mechanisms of impact, which were derived from a previous study (Laudel and Gläser 2012), led to empirical typologies and enabled both the identification of change and its causal attribution to WWTF grants.

For a study like this it is very important to secure confidentiality of the interview accounts, both for the sake of the interviewees (the protection of their privacy) and in order to secure the quality of the investigation. If inter- viewees perceive the possibility of 'leaks' to the funding organisation, the likelihood of distorted - socially desirable - responses increases because interviewees may consciously or subconsciously want to please the funding agency that may fund their future research. With one exception, the WWTF does not know which grantees I selected. The exception is the VRG Leader programme, for which I was asked to include all group leaders.

While the identity of some of the interviewees may be known to the WWTF, the WWTF does not have access to the interview transcripts. In this report, I took care to select quotes from interviews in a way that prevents readers from identifying the researcher. Ensuring this requires not only omitting names but also details of the research, locations, and institutions. Quotations will only be linked to the type of the grant the interviewee held or currently holds (VRG leader, Science Chair, or Project Grant), and to the discipline (LS = Life Sciences; IT $=$ Information and Communication Technologies; $\mathrm{MA}=\mathrm{Ma}$ thematics). If it is likely to make interviewees identifiable, even this information is omitted. This loss of detail and specificity can be regretted but is unavoidable, not the least because the WWTF funds only few projects in each of its programmes.

Before presenting the results, I would like to explain how they can be or cannot be read. I conducted a qualitative study which, in spite of relatively small numbers of interviewees, leads to conclusions about the impacts of the WWTF funding schemes. The reader is asked to keep in mind that there are more ways to arrive at causal statements than the interpretation of statistical associations between variables measured for a representative sample of interviewees. The argument here is based on the demonstration that research with certain properties was funded by the WWTF. Thus, whenever the conditions specified in this report are present, the WWTF is likely to have the impact described in this report.

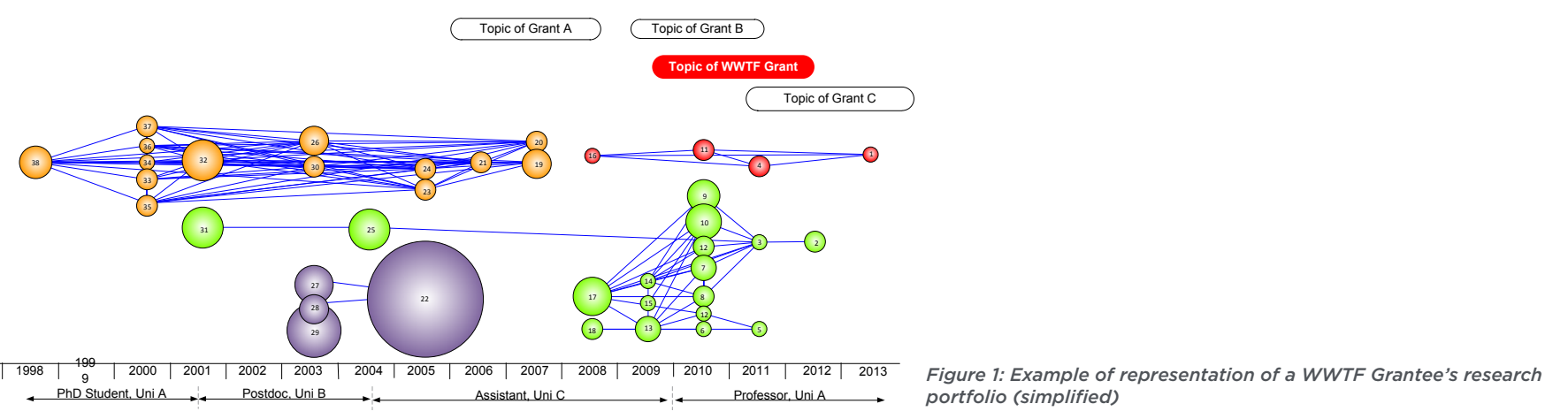


The following brief characterisation of the investigated funding programmes distinguishes two types of funding. Project funding (3.1) grants funding for a specified project that has a clear aim and specifies approaches and resources that are necessary to achieve this aim. In contrast, programme funding (3.2) grants funding to a person for pursuing a somewhat broader, less specified aim. It includes funding for the position of the applicant. However, it is different from fellowships in its allocation of considerable resources, usually for more than one research project.

\section{II Project funding}

This funding instrument finances research in specified areas for a period of two to four years. The minimum amount of funding is $€ 200,000$. The formal maximum limit is 1 million Euros, although informally the limit lies by about $€ 800,000$. Funding covers all resources needed for conducting research except major investments in equipment, i.e. costs for personnel, small project-specific equipment, consumables, and travel (WWTF 2008a: 24). Applicants can also apply for their own position, a condition that is of particular interest to early career researchers.

The major selection criteria for proposals include

- "Scientific excellence of the applicants: track record of principal investigator and partners; quality of project management, cooperation and networks

- Quality and innovativeness of the planned research (work packages)

- 'Prospective benefits': potential medium-term or long-term economic and social benefits of the suggested research project." (ibid.: 24)
Three project funding programmes have been selected for the impact study. In the Life Sciences, three calls (2003, 2005, and 2009) focused on the identification of molecular mechanisms and/or the development of methods for this purpose. Interdisciplinary and cooperative approaches have been strongly encouraged (but were not regarded as "musts"). (ibid.: 28; Life Sciences Call 2003, 2005, 2009).

Another thematic focus in the life sciences was "linking research and patients' needs". In the framework of these calls (issued 2007 and 2011), proposals for hypothesisdriven research aimed at strengthening links between basic research and clinical/disease-related research were invited. With this orientation, collaboration between basic scientists and clinicians should be fostered.

With its programme in mathematics, the WWTF wants to encourage projects that apply pure mathematics in other disciplines (e.g. utilization of an innovative mathematical method in modelling and simulation). The projects should be developed by interdisciplinary teams (an applicant from mathematics will need a partner from another discipline or vice versa) and be designed to (further) develop innovative mathematical methods (WWTF 2008a: 30). The idea for this programme is based (a) on the assumption that mathematics and mathematical tools can positively influence other fields of sciences, and (b) on the observation that Vienna has a strong tradition in the field of mathematics. Three calls were launched so far (2004, 2007, 2009).

In the field of information and communication technologies the WWTF aimed at substantial scientific questions which offer the prospect of medium-term utilisation and exploitation (WWTF webpage). Three calls were launched so far (2008, 2010, 2012). 


\subsection{Programme funding}

Two of the investigated programmes provide programme funding for researchers. The instrument WWTF Science Chairs aims at recruiting outstanding younger or already established researchers from abroad to Vienna. Applicants must have worked abroad for at least five years. The Science Chairs are intended to further strengthen fields that are already well developed or to establish fields that are identified as gaps in the Viennese research landscape (WWTF 2008a: 25). The position of the Science Chair, a small research group of postdocs and PhD students, recurrent costs and some initial investments can be funded for four to five years. The maximum amount is 1.5 Million Euros. The main selection criteria for Vienna Science Chairs are:

- Scientific excellence of the candidate and her / his research activities,

- a Strategy for embedding of the new team into the existing research environment, and

- Commitment of the candidate and the applying institution including long-term planning (ibid.)

The research organisation must prove its commitment by in-kind contributions and by clear plans for the fu- ture of the research area in which the Science Chair is established. This commitment includes the creation of a permanent chair in the field after the term of the Science Chair, for which the professor who held the Science Chair can apply. Research organisations select a candidate and apply together with the candidate for WWTF funding. Since 2004, eight Science Chairs have been funded.

The second, more recently established instrument funds Vienna Research Groups for Young Investigators. The VRG Leaders programme differs from the Science Chair programme in its target population, which consists of researchers at an earlier stage of their career. The programme aims at attracting promising young researchers from abroad to build up their first „own" research group in Vienna and to give them a long-term perspective at the research location Vienna. The maximum amount is 1.5 Million Euros for a period of six to eight years (WWTF website). The application procedure is similar in that research organisations select candidates and apply together with the candidate for WWTF funding. Researchers are offered a tenure-track position. Since 2010 seven such groups have been funded. 


\section{THE IMPACT OF WWTF FUNDING ON INDIVIDUAL RESEARCH PORTFOLIOS}

\section{I Does the WWTF funding support changes in re- search?}

The overarching intention of all WWTF funding is to support research that is excellent, interdisciplinary, and has an applied aspect in the mid term. This can be achieved either by selecting such research and supporting its continuation and extension, or by enabling the emergence of such research. While both modes of support are important for the progress of research, enabling change has the additional benefit of promoting intellectual innovation and increasing the diversity of research. Enabling change is also of particular importance when early career researchers and their transition to independence are supported because gaining independence with an excellent research programme can have an impact that lasts a whole career.

While the assessment of the excellence of funded research is not possible with this study, it was possible to reconstruct the ways in which researchers used the WWTF funding to change their research, and to deviate from the mainstream of their communities. The form of continuation or change of research depends on the structure of a researcher's portfolio. Based on the observation that researchers move through sequences of thematically related projects ('research trails' or 'lines of research'), we can distinguish two types of research portfolios, namely those consisting of only one line of research and those including several lines of research that are worked on in parallel. We found both types across all three funding programmes, disciplines, and career stages, although early career researchers generally (and in the sample studied here, too) are more likely to have only one line of research (yet). Figure 2 shows an example for a research portfolio with one line of research; on page 8 is an example of a research portfolio with two lines of research.

We can cross-tabulate the two types of research portfolios with a similar distinction of financial portfolios, namely the distinction between WWTF funding being the only source or one of several source of project funding. Four combinations result, all of which were found among the 25 interviewed researchers (table 1).

How was WWTF funding used in these situations? The study found WWTF funding supporting the continuation and broadening of existing lines of research. Some of these extensions included interdisciplinary collaborations:

The phenomenal thing was that we were able to link up with clinical studies, with material from patients. In the clinical study, these patients receive several of these new [drugs]. Thus, in addition to our own results we also have the results about the patients, and can compare them and can ask whether what we do in the [animal model] can be applied to the patient at all. [...] And we have exactly the same results with patient cells in the [animal] as they had with patients in the clinical trial. Thus, we actually have a real system we can use to test which drugs have an effect on which patients. (LS, project grant) ${ }^{2}$

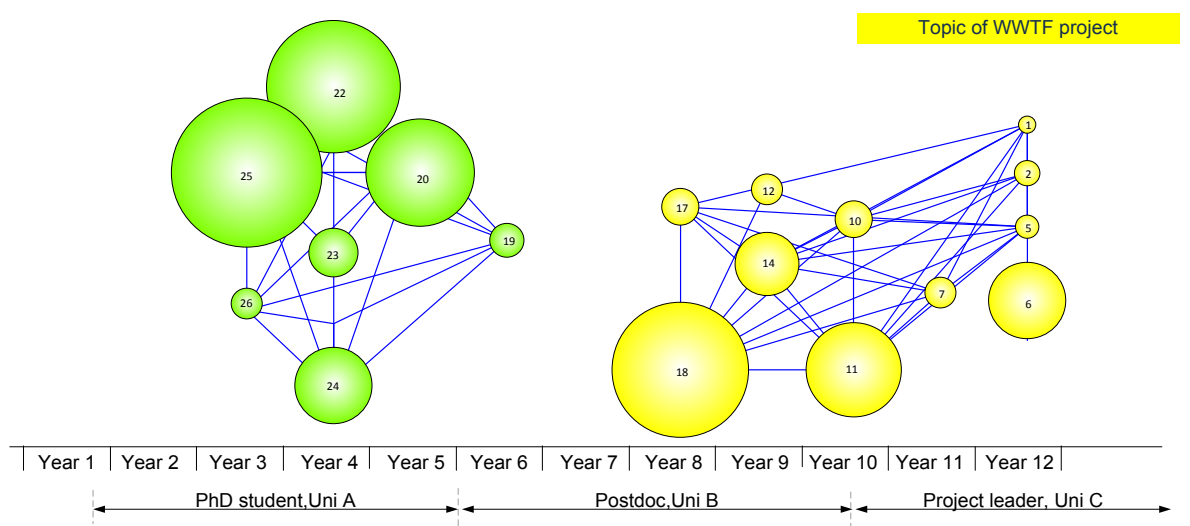

Figure 2: Example of representation of a WWTF Grantee's research portfolio (simplified)
2 All quotes in German language were translated by the author. 
WWTF funding also supported new lines of research. This happened mostly by funding the beginning of additional lines of research. However, there was at least one case in which a WWTF grant was used for a major change of research, which consisted of abandoning the only line of research and beginning a new one.

From [former lab] to [Vienna lab] I completely changed the topic. It was still [the same biological process] but a completely different aspect. So, the first part of the postdoc was [topic 1]. It stayed in the [former] lab. The second part was [topic 2]. And then I got more involved in that and looked how it works. And that is what we still do here. (LS, programme grant)

Several interviewees reported that they used the opportunities provided by WWTF funding for activating 'dormant' lines of research, i.e. topics they had been interested in for a long time but could not work on for a variety of reasons. Conditions for such an activation included the new research environment for incoming researchers, as in the following case:

I think I visited here once more but then there were some quite intense discussions about what [researchers in the university were] doing, what I was doing. And there we tried to find the cross links between what I thought was important in the projects that I wanted to do, indeed it is a continuation [...], the [topic 1]. [Topic 1] of course is something that has always interested me so that was more of a continuation. [Topic 2] was something that we were just a little bit getting into it. It was typically one of the things that I really wanted to do but couldn't do [at my old university abroad], I wasn't able to really focus on that. We were able to start with it but we couldn't get really much worth it. That was something that I really wanted to develop more. (LS, programme grant)
In other cases, the demand for interdisciplinary collaboration let researchers begin new lines of research:

The group of [Co-PI] is strong in this area. Therefore we said okay, let's have a project on [topic]. Our (my group's) area of interest here is in [field A], and their interest is in [field B]. And that's how we applied for the project. (IT, project grant)

In each of these cases, the WWTF achieved at least one of its various aims, and the hoped-for mechanisms operated: Researchers who came to Vienna for WWTF funding exploited synergies with their new research environment, expectations of application-orientation and interdisciplinarity led to the selections of applicants who explored new opportunities for local collaboration, and other researchers used WWTF funding for major changes of lines of research.

Another question that has become increasingly important for funding agencies addresses the relation of research to the mainstream of fields. Peer review, which most funding decisions, has acquired a reputation of promoting 'excellent mediocrity', i.e. very good or even excellent research that is somewhat conventional, otherwise it could not pass the peer review (e.g.Chubin and Hackett 1990; Travis and Collins 1991;Berezin 1998). This is why funding agencies increasingly attempt to gear their funding not simply to excellence but also to more unconventional research (Heinze 2008, Lal et al. 2011, Luukkonen 2012).

In my investigation of funded projects, I looked for two properties of research that make it unconventional, namely risk-taking and deviation from the mainstream. Both properties occurred in several projects. Risk - the possibility of not achieving the project's aim - occurred due to strategic uncertainties (not knowing whether the

\begin{tabular}{|l|l|l|c|}
\hline \multicolumn{2}{|c|}{} & Funding portfolio & WWTF and other funding \\
\cline { 3 - 4 } \cline { 3 - 4 } Research portfolio & Only WWTF funding & 3 (incl. 1 ECR) \\
\cline { 2 - 4 } & One line of research & 9 (incl. 8 ECR) & 9 (incl. O ECR) \\
\hline
\end{tabular}

Table 3: Types of research and funding situations of WWTF grantees (ECR= Early Career Researcher) 
aim can be achieved at all, first quote) and technical uncertainties (not knowing how the aim can be achieved, second quote).

Well, there are certainly parts of the project which might turn out not to work on large programs. There are certain approaches of which we are not sure yet that they will scale up. In principle, we are convinced that this is a method that gives us the results that we want to have, qualitatively. The question is then, whether they can be applied to large programs, to industrially interesting programmes.

$$
* * *
$$

The [...] WWTF project was based on breeding certain [organisms] in larger quantities. Some experiments only work this way. And this was incredibly difficult. Now we have it under control but that was really a long way. And this has set us back at least one and a half years. [...] This we didn't expect this at all. We had to find a cultivation method [...]. It felt like an eternity, but now it works. (LS, project grant)

I found projects that were laden with these kinds of uncertainties across all three disciplines, and across all funding programmes. The same applies to the second property, deviation from the mainstream. The most obvious of these deviations is contradicting the majority opinion of one's scientific community.

This is indeed a very risky topic, partly also very polarising because for a long time, it went against the received opinion that there are these [effects] ... Many people don't believe it. And this is not surprising. (VRG)

Another version of non-mainstream research addresses a community's 'blind spot' by doing something that does not contradict any majority opinion but has not yet been done simply because nobody else seems to have thought of it.
Then we had discussions at one of the conferences, and realised that in all these [models], [one phenomenon] is not modelled at all. [...] And then we somehow decided that it would be a great project to include [this phenomenon] in these [models]. [MA, project grant]

A specific case of this blind-spot phenomenon is the application of non-mainstream approaches or methods to mainstream problems.

The [...] groups in the field do either really hardcore biochemistry, that is analysis of structures, or they do more genetics, cell biology. We do the soft biochemistry in between. That's something hardly anybody does. Especially this [analytical method]. This is a technique not everybody masters. But we do it very well here [...]. And this lets us look at things with a method different from those of other people. [LS]

Also, some theoreticians who belonged to a specialty that was strictly focused on modelling and simulation started to include experiments in their research portfolio.

Finally, non-mainstream research includes attempts to link communities that have no previous connections. Such links are created by combining approaches from two communities in one experiment, or by demonstrating the relevance of one community's empirical object to the research of the other community.

I would also consider myself as multidisciplinary. On of my scientific communities is [...] in mathematics. But I also do signal processing, that's about the application, how can we represent or calculate signals. Then I have the areas of application, too [...]. They are relatively decoupled from each other. What is fascinating about this is that you can contribute ideas from different areas. (MA, project grant) 
This happened to several mathematicians, which indicates that the specific expectations inscribed in the WWTF funding programmes led to the self-selection and selection of applicants interested in this kind of research. Again, at least some of the findings indicate that the hoped-for selections of researchers and research occurred.

Not surprisingly, the effects reported here - changes in lines of research or unconventional research - did not occur in all investigated projects. As a previous investigation of the ERC demonstrated, some 'business as usual' will inevitably be funded because it is excellent, if nothing else. Similarly, the existence of perfectly mainstream projects in my sample indicates that deviating from the mainstream may be a frequent property of excellent interdisciplinary research but is by no means a necessary one.

\subsection{How are the expected mid-term societal benefits of research funded by the WWTF achieved?}

Over the last decades, the societal expectations of benefits from research have grown in many OECD countries. There are many reasons for that, which include, among others, the growing costs of research, the increasing dependence of the economy on science-based industries and innovations, and the spread of the perception that science in fact can contribute to solutions of societal problems. Political expectations of utility have risen, and are now part of many policies and governance instruments.
At the same time, these expectations are very difficult to operationalize and to turn into criteria for allocating funding. There are many links between research and applications, which vary in content and strength. These links are based on the problems, objects, and methods of research (Gläser 2000). Consequently, they constantly change with the new knowledge that is produced in other research processes. This is why both the nature of societal benefits and the time horizon of their arrival are often difficult to predict.

WWTF funding for project grants aims at "a potential medium-term or long-term economic and social benefits" (WWTF 2008a: 24). In the light of the above-mentioned difficulties, this criterion appears to be sensible because it is sufficiently flexible to accommodate the variety of links between research and application as well as disciplinary differences. The links of the investigated projects to applications varied from very weak to very strong, and were realised in different ways (table 4).

Project grants in the mathematics and the life science programmes were all aimed at solving research problems of the respective scientific communities, i.e. they had a basic research aspect. Two projects clearly had a very long-term perspective, namely the assumption that their results may eventually be beneficial for human health or the environment. While this is likely to be true, the fact that no such benefit could be specified and timed suggested that these projects would overstretch the definition of application-orientation. Therefore, they are considered as purely basic research.

In five other cases, links to applications were realised through collaborations of basic researchers with researchers from other fields who worked close to application contexts, e.g. engineers or clinicians.

\begin{tabular}{|c|c|c|c|}
\hline Basic/applied character of research & LS & MA & ICT \\
\hline Purely basic research & 1 & 1 & \\
\hline Collaboration with application-oriented researchers inside university & 3 & 2 & \\
\hline Research question triggered by application problem & 1 & 3 & 5 \\
\hline Collaboration with users from industry & & 1 & 1 \\
\hline
\end{tabular}


And the point was after many years essentially doing [fundamental research] I wanted to see some applications like how can I use them in practice. But now the people here with whom I was working weren't doing applications. I saw the WWTF Call that was "Mathematics and ...", they were searching for applications. And then I heard that there was someone in [another] university [...] I contacted this professor there. And we had a meeting and we even saw that there were many things that could have been done together. I mean, he was really applying those [mathematical tools] without any theoretical background; I was just making the theoretical thing, so like let's try it.(MA, project grant)

In other cases, the research itself was of a more applied nature because the questions underlying the projects were triggered by societally relevant questions.

The application area was then [...] because it was known since the 90s that we may face a [crisis] [...]. That means a contribution to reducing the independence from this [substance]. Methodologically, it doesn't change a lot. But there is always the question how do I position myself in a way that somebody finds my models interesting, or that I really can contribute something - which applications are important? (MA, project grant)

Not surprisingly, the investigated ICT projects had a more strongly applied character. Fields differ in their distance from applications, and for most of the ICT field the distance is rather small. An applied character did not necessarily imply a collaboration with partners from industry. However, two researchers had follow-up projects with industry partners after their WWTF-funded projects, which fits the WWTF's expectation of "mid-term benefits".
If I were to say which one is the most important [project], than it is the WWTF project. Indeed, I would call it the backbone project. Precisely because it is fundamental research. [...] And what has been added is more application-oriented projects. [...] Additionally it triggered that the applications bear questions that are also scientifically challenging. (IT, project grant)

This quotation emphasises the bridging function of the WWTF project as application-relevant fundamental research.

In two of the investigated cases, the link to application was realised by a collaboration with users from industry.

Q: And the collaboration with [partner from industry] in this project, how was it conducted. So, who did what?

A: The collaboration was - we have many joined publications. And this was actually a permanent contact, a lot via phone, emails.

Q: You also had a joined PhD student, didn't you?

A: The situation was that [X.] was employed as a postdoc. And later he still collaborated with [partner from industry]. Well, this was very, very intense. (project grant)

This overview indicates that the WWTF criterion of "potential medium-term or long-term economic and social benefits" and the selection process is flexible enough to solicit and support a variety of links to applications. While a stronger criterion and its control would be possible, the resulting changes of self-selections of applicants and selections by the WWTF would not necessarily be beneficial. Since several criteria are applied in the selection processes, making all of them equally strong enforces compromises, and the quality, interdisciplinarity, or contribution to the Viennese research landscape 
3 While window dressing can never be completely prevented, it is rather unlikely in the case of "Mathematics and

" because it would require to invent a collaboration between a mathematician and a colleague from another discipline which convinces the reviewers and then not to collaborate. The transaction cost of this kind of window dressing would be so high that it is easier to actually collaborate in most cases.

might suffer. Even with the current formula, the question may be asked whether self-selection processes among potential applicants prevent projects that rank high on all other criteria from being submitted because the applicants feel unable to describe medium-term or midterm social benefits.

\subsection{How does the WWTF achieve interdisciplinarity?}

Promoting interdisciplinary research is one of the central aims of the WWTF (WWTF 2008a). The WWTF approach to promoting interdisciplinarity is interesting because it is located somewhere in between two extremes. Funding programmes for interdisciplinary research can be thematically neutral and completely investigator driven, as for example the programme 'Collaborative Research Centres' of the German Research Council (Deutsche Forschungsgemeinschaft). In this programme, proposals can be on any topic. Planned interdisciplinary collaborations are a prerequisite for funding, and their possibility and preparation by the applicants is carefully checked by the review panel. Funding programmes can also promote interdisciplinarity by defining an interdisciplinary topic (e.g. sustainability research or biomathematics) and funding projects on this topic, which then can be expected to be interdisciplinary if they fall into the scope of the call. The WWTF tries to achieve interdisciplinarity by a strategy that lies between these extremes. Its funding schemes define a broad area and require specific partnerships between disciplines in that area. These partnerships can be realised in different ways because several specific instruments are available.
For example, the funding scheme "Mathematics and ..." equires pure mathematicians to collaborate with researchers from other disciplines in order to boost the application of methods from pure mathematics in other disciplines. Within this thematic area, project grants, VRG Leaders, and Science Chairs are funded. The required proof of collaboration with another discipline ensures that regardless of the specific conditions of funding, the aim of interdisciplinarity is very likely to be achieved. ${ }^{3}$ In several cases mathematicians tried to find partners they didn't had any or only loose contact before:

We explicitly tried to do something together within a project. Previously, we now and then talked to each other and saw we do mathematics that could be interesting for [area of application]. And yes, you always talk to each other but then you never have time to work on it intensively, to look for research topics. And the WWTF call ... there we had the opportunity to do something concrete, to try something together, a joined proposal with these problems. (MA, project grant)

New interdisciplinary collaborations were prominent among mathematicians. Although this is largely due to self-selection, it also becomes clear that the funding opportunity made mathematicians actively seek new collaborations outside their discipline.

The programme "Linking Research and Patients' Needs", which uses only project grants as instrument, operates in a similar way. Again, the emphasis is on collaborations, this time between life science researchers and clinicians. Among the investigated projects were two of biologists who started collaborations with clinical groups when the opportunity for funding occurred.

Well, we specifically selected him as a partner. [...] We have an [...] interest group where clinicians and pre- 
clinicians meet once a month to exchange ideas and present data and so on. And he was a member as well. So I already knew him very well and asked him if he was interested to take over the clinical part of this work. (LS, project grant)

The degree of interdisciplinarity certainly differed between programmes and instruments. This should not be seen as a problem, however. Similar to the argument about societal benefits, it would be wrong to conclude that more interdisciplinarity is always better. An interesting case is a researcher who started a completely new collaboration in an area that traditionally has close connections to mathematics. But even in this not-so-unusual interdisciplinary collaboration, severe communication problems between different scientific languages had to be overcome:

I contacted this professor there. And we had a meeting and we even saw that there were many things that could have been done together. [...]But of course it was a high risk project, we didn't meet each other at all. We just met once. I wrote the application. It was funded. But it was really risky and it was very hard. [...] Because I was doing just theory, he was doing just applications, it was like we were talking different languages. (IT, project grant)

The collaboration did not continue after the project was finished. However it triggered another collaboration between the interviewee and researchers from a more remote field. It is unlikely that this collaboration could have been conducted at all without the previous 'training in interdisciplinarity'.

Thus, while it is not surprising that the WWTF funded several projects of researchers who already had strong interdisciplinary collaborations and utilised WWTF funding to maintain them, in many cases the somewhat unusual conditions inscribed in the funding instruments initiated the active search for interdisciplinary collaborators and collaborations. WWTF grantees also could and did - use their funding for internal interdisciplinary collaborations, namely by recruiting researchers with a complementary expertise as postdocs.

Interdisciplinary collaborations were also promoted by the procedure for establishing Science Chairs. Owing to the joint search of the university and the candidate for the optimal fit, the Science Chairs had many collaborations, among them many interdisciplinary ones:

And I really had the feeling of being welcomed so there were many experimental groups here from the beginning coming like find it nice that you are here. Can we do something? We have this problem could you have a look and we have a look together what will be your ideas, sometimes also impossible expectations maybe but it was very nice and that played a very broad view again on much time all kinds of different applications where we could use our methods and we really could develop our methods further on the new site. [Science Chair]

The fate of collaborations after the end of the funding periods reflects interesting disciplinary differences. In mathematics and computer sciences, the collaboration underpinning the funded project often ended with the project because the problem for which the specific combination of expertise was necessary was solved without leading to further interesting problems that required the same combination of expertise.

And I think it went really well. The collaboration between the groups wasn't that close, one may have to admit. We jointly supervised a doctoral student. These are all joined publications; we wrote one or two articles together. But this was it, the commonality. I think that each of the groups involved was very suc- 
cessful in the project and this way gained a reputation in some niche. (IT, project grant)

Although this was a frequently occurring situation in mathematics and ICT projects, some collaborations also endured.

With this project I also established many important research collaborations. I have research collaborations with [a university abroad]. This was very important. It brought me into [EU network]. And there I established collaborations all over Europe. (IT, Project grant)

Many collaborations in the life sciences that were triggered by WWTF funding were continued beyond the funded project. In these fields, in which lines of research consist of sequences of projects requiring similar combinations of expertise, WWTF funding helped researchers expanding their collaboration network.

The majority of the new collaborations linked researchers in Vienna. On first glance, this looks suspicious because researchers generally look for the best available collaborators regardless of their location. However, the discrepancy can be explained by the selection of applicants that fit the Viennese research landscape. Since one of the criteria for the selection of VRG group leaders and particularly Science Chairs is that they had to come from abroad and to fit in the local research environment, new local collaborations are very likely to occur. Furthermore, local collaborations are advantageous for many research processes because they can be based on face-to-face communication. Thus, the simultaneous requirements of recruitment from abroad and local fit also made WWTF grantees in the VRG Leaders and Science Chairs programmes restructure their collaboration networks and tie them into the local research environment.

While the initiation and promotion of interdisciplinary research through specific calls that coupled loose the- matic expectations with expectations concerning collaboration appears to have worked very well, and was regarded by applicants as having triggered innovations in interdisciplinary collaboration, this approach is not without risks. The combination of expectations the WWTF writes into its calls for proposals must 'work', i.e. must solicit the 'right' project proposals. Comments by interviewees on one of the last calls "New Ventures Beyond Established Frontiers", indicate that the expectations might escalate and thereby prevent researchers from applying because it looks as if nobody can meet the expectations.

And the other thing was this recent [call], the very innovative new things and many people I heard were rejected because it wasn't interdisciplinary enough because it didn't work with two weird groups together. [...] Yes if that's the aim then the science is no longer the aim. [...] I think they should be careful not to go too much into coming up with new obscure calls where then basically hardly anyone fits. [...] But I think it would not hurt to stay a little bit closer to traditional calls for projects on a certain theme. [...] But [...] they come up with these wild ideas of super interdisciplinary that everyone tries for that then you get your 100 applications.

\subsection{Durability of research changes}

An important aspect of a funding agency's impact on individual research and the research landscape is the durability of the changes that occurred. Unfortunately, this question is the most difficult to answer. The funding activities of the WWTF are simply too recent. It is impossible to know about any long-term effects because 
the 'oldest' projects funded by the WWTF have finished a mere six years ago. For one programme, the VRG Leaders, we cannot know anything about longer-term effects because the first projects in this programme are not yet finished. In many other cases, the projects are very recent.

What we do know with some certainty is that the structural changes initiated by WWTF funding are certain to last (see 5.1). The Science Chairs programme has triggered the creation of new permanent chairs in the fields in which Science Chairs were appointed. The VRG Leaders are appointed to tenure-track positions, which means that it is at least very likely that the research programmes of some of them will be continued in Vienna.

The durability of changes in research are more difficult to assess. Furthermore, any assessment is asymmetric: If the topic of a WWTF project is discontinued, this is likely to stay that way. If, however, a topic that began with a WWTF project is continued for three years after the project ended, we cannot know whether it will still be continued after four years.

With these limitations in mind, we can look at the changes in research described above and assumptions of interviewees about the permanence of these changes. These assumptions and plans vary between disciplines. Many projects in mathematics and informatics are 'isolated' in the sense that they have well-defined ad hoc - relations to other fields and don't generate new problems when solved. This is why WWTF-funded projects in these fields did not initiate new lines of research but were not continued after being solved.

Overall this WWTF Call was very important to our research group. However, you could say that the project lasted three years and we essentially did what we planned in the proposal. (MA, project grant)
In some cases, the new projects built on ideas that emerged in the previous WWTF-funded projects.

This $[. .$.$] in a sense emerged suddenly. We didn't anti-$ cipate at the time [of the application] that this would become our main research area within information [...]. (IT, project grant)

$$
\text { *** }
$$

Well, this project was very, very important for developing further questions. It was not that important for me to receive the money or that I got publications but that I developed many other questions from that. [...] I developed three important research directions from that. (IT, project grant)

Taking into account the bounded nature of problems, an interviewee voiced concern about the WWTF's expectations of long-term research programmes for the VRGs.

But when I remember that they had to provide a research perspective for eight years for this [VRG] call - this is impossible in mathematics. You can do that if you fight cancer, then you might have a time horizon of 20, 30 years. But in mathematics if somebody knows what they will do in five years' time then this is no research anymore. Well, these are things that should be considered (Mathematician).

This concern was confirmed by a VRG leader who described his research programme.

Also, the duration of the project is planned for five to eight years. However, when it approaches later phases the project description is of course vaguer because it is very difficult to plan research so far ahead. I can hardly promise what I will do in eight years because it can change very quickly. (IT, VRG leader)

In the biosciences, however, the projects and particularly the VRGs funded by the WWTF helped establish research programmes the grantees believed to last. 
Q: For how long is this planned? Is this now a lifelong project or ...?

A: Infinitely, yes. The fact is that you find something and then you have the next ten questions. And then you find again something, and then the next ten occur. [...]

Q: But the title [of the grant] ...

A: ... will stay for a while, I am pretty sure.

Q: A while would be decades?

A: I think so because it is a large concept. And it would need a really new finding that one suddenly moves somewhere else (LS, VRG)

Q: These [...] research topics - for what time horizon are they designed?

A: That's why I went so far, actually they are designed forever. [...] This is nothing you can finish in five years. Of course there are always intermediate goals. One wants to publish and this is why the projects are planned in small chunks. But the overall idea is planned to be very long-term.

It is important to note that of course the durability of research plans that evolved on the basis of WWTF funding crucially depends on continued success in acquiring external funding. Several researchers intended to continue their research from WWTF project grants but couldn't due to the lack of funding.

Well, this clinical matter is of great interest to me, the clinical trial. That would be an important matter which can't be realised due to the lack of funding. (LS, project grant)

What happened with the project? It found some resonance $[. .$.$] in the community. That's the one thing. The$ other thing is, of course there are follow-up questions that we would like to do. Two of them we would have taken up. One follow-up project that we tried to get funded is not yet funded, unfortunately. (IT, project grant)

Generally speaking, the effects of the WWTF funding on the research portfolio of early career researchers were stronger because the grants kick-started their autonomous pursuit of research programmes. This is particularly apparent for the VRG Leaders but project grants also played a crucial role in that respect. 


\section{DOES WWTF FUNDING HAVE AN IMPACT ON THE . RECIPIENTS' CAREERS?}

Before I discuss other aspects of the impact of WWTF funding on careers in detail, I would like to address a cross-cutting theme, namely the role of gender. This discussion is restricted to the volume, structure and use of grants. The WWTF's selection procedure, a possible bias in this procedure, or counter-measure to such a bias were not within the scope of my study. ${ }^{4}$

In order to check for gender effects in the use of WWTF grants, I interviewed male and female grantees from the VRG Leader and the project grants programme (there are no female Science Chairs).

While I did not find any differences between male and female researchers in the use of grants, relationships of grantees to their research environment, or recognition received and reputation accrued for funded research, it turned out that WWTF grants fulfilled an interesting function for several women who received Hertha Firnberg or Elise Richter grants from the Austrian Science Foundation (FWF). These grants, which have the purpose of promoting women's careers, are fellowships which fund very little beyond the grantee's salary. This makes them insufficient as research funding, particularly in the empirical sciences. The WWTF project grants helped filling this gap in several cases by providing the funding that was necessary to actually conduct research on the positions funded by the FWF.

[The grant] - this was nice for me and prestigious and great. But if I would have had only that then I could have done exactly zero. (project grant)

$$
* * *
$$

I had my [project], so I was self-funded. But there you are limited, of course, what you can do, because apart from you salary there is not much money there. You get a lump sum, I think a couple of thousand Euros per year [...] And you have to pay conferences and everything from that. So I was generally interested to apply for another grant. And then there was this call from the WWTF. (project grant)
External funding - funding that is not provided by the researcher's organisation - affects careers in several ways. In this section, I discuss three ways in which grants affect researchers' careers, namely by

- providing a position for conducting the grant-funded research, or an opportunity to create or shape such a position;

- providing early career researchers with the opportunities to begin independent research; and

- improving the grantees' chances of success in later recruitment processes.

The first two effects of grants can be called direct effects because they are immediate consequences of applying for and being awarded a grant. The third effect is more indirect in that they are achieved through the use of the grants.

\section{I Direct effects of awarding grants}

\section{Providing a position}

Grants that directly shape a career phase by providing a salaried position have the strongest and most obvious impact. In addition to this institutional impact, there are two ways in which grants can affect careers indirectly, namely through their material value, i.e. by enabling research that increases the grantee's reputation in their community, and through their symbolic value, i.e. as a signifier of performance.

Direct institutional effects are a constitutive part of two of the WWTF programmes, namely the Vienna Research Group (VRG) Leaders and the Science Chairs programmes. The $V R G$ programme requires the group leader to hold a tenure-track position at a university in Vienna, which means that the successful grantee has the oppor-

4 It should be mentioned that for some time women have been particularly encouraged to apply for WWTF grant funding. The promotion of women is also included as a criterion into the application procedure for science chairs and VRG leaders. For example research organisations that apply for a VRG grant have to describe "the concrete steps undertaken during recruiting and selecting the leader of the proposed Vienna Research Group" (WWTF 2010: 16). Determining the effect of these measures would require a thorough investigation of peer review processes and outcomes. 
tunity to become tenured after five or six years. The positions are provided by the university. The Science Chairs programme operates in a similar way: the position of a Science Chair itself is created for a fixed term of five years. However, they are awarded only if the university hosting the Science Chair promises to create a professorial position in the field of the Science Chair holder. Similar to the tenure-track positions, the Science Chairs have strong prospects of being appointed to the new professorial positions but no guarantee.

The problems of this construction have been extensively discussed in previous evaluation studies (Edler 2007, WWTF 2008b). They were reiterated by the interviewed Science Chair holders, although an additional selection process did not deter them. However, the excellent researchers the WWTF wants to appoint as VRG leaders and Science Chairs can be assumed to have competing offers of permanent positions, which they might prefer compared to the inevitable risks of additional evaluations. Since researchers who want to avoid this risk might not apply to the WWTF programmes at all, it is difficult to tell whether Vienna has lost strong applicants for this reason. All past WWTF Science Chair holders were tenured after the normal appointment procedure for Austrian professorships.

International mobility was a common characteristics of the interviewed grantees. VRG and Science chair grants required international mobility - the applicant had to come from a research organisation abroad. Indeed, all eight grantees moved from abroad to Vienna. From the researchers who applied for project grants one was abroad at that time and two only recently had moved to Vienna from abroad.

Why do researchers come from abroad and take up WWTF grants? All of the researchers who took up a position of a VRG Leader or a Science Chair had alternative career options, which included
- the German Emmy Noether Fellowship or an SNF professorship in Switzerland, which is comparable to the position of a VRG leader,

- an extension of a postdoc position in a highly reputed research group, and

- tenured positions (of a full professor or a group leader at a non-university research institute).

Nevertheless, all interviewees who had these choices decided in favour of the WWTF-funded positions. Not surprisingly, their reasons for this decision varied considerably and included

- the tenure-track option offered with the WWTF position (VRG leader);

- the amount of resources that were offered with the position (Science Chair);

- the autonomy provided by the WWTF position (VRG leader, Science Chair);

- the attractiveness of the research environment and the collaboration opportunities in Vienna (all grant types),

- the flexibility of the WWTF in negotiating specific working conditions, which exceeded that of other funding agencies (VRG leader), and

- cultural and private reasons to come to Vienna (all grant types)

As it is often the case with career decisions, it was usually a mix of research-related considerations and other considerations.

However, at an individual university you wouldn't have something comparable, at least not in my field. I got really excited that there is indeed this opportunity of having many people at one place. They have not necessarily overlapping expertise but expertise that fits together. And to collaborate was an important reason for me to come [...]. (programme grant) 
You have good opportunities at [German Max PlanckInstitutes], however, this would have been a directly subordinated position. And here I have complete independence. And with the WWTF grant I got far better resources of course. (programme grant)

***

Well, I would have [...] felt very uncomfortable to take up this position in [North America]. On the one hand, I didn't feel like I want to emigrate, leave Europe forever, so to speak. And then also, [...] the university has such a satellite campus [...] which wasn't very attractive. In addition to that, being a theoretician, I would been totally on my own. [MA, project grant]

These reasons are not specific for WWTF-funded positions. Similar reasons were mentioned for career decisions to give up positions abroad and take up or keep a position in Vienna.

\section{Q: And why did you choose Vienna?}

A: Well, first of all I was long enough at [university abroad], and secondly the funding of this research location there somehow let the [...] sciences fall behind. And here I got a very good offer, I found good working conditions. We have here I think a concept of [...] centred research [...] and not methodically centred research, which I value. [...] These were the main reasons why I choose Vienna. (LS, Project Grant)

Researchers already based in Vienna declined offers from abroad for the already mentioned reasons.

Another opportunity to directly modify one's career is provided by the WWTF project grants. Part of the grant can be used to fund the position of the grantee and thus to extend a fixed-term position or to create one. This opportunity was exploited by two interviewed grantees. However, project grant holders on temporary positions don't have clear career prospects. Austrian universities provide only few tenure-track positions ("Laufbahnstellen") or tenured positions ("Assoziierte Professur").

Any planning of a career in Vienna is difficult. I have built up something for me. I created a momentum and I would like to continue. But it is not possible that you can stay if you have achieved this and that. This is just not possible. And this is a big gap. [IT, project grant]

As a result, some of the WWTF grantees who received excellent offers from abroad but wanted to stay in Vienna did not find an opportunity to do so.

\section{Becoming independent}

Enabling independent research of early career researchers is among the priorities of many funding agencies all over the world (NRC 2005: 4, Jonkers 2011). The WWTF is no exception here, and its funding programme for VRG Leaders explicitly aims at supporting the independence of early career researchers. Similar to the ERC; the WWTF applies a rather wide definition of 'early career' by extending eligibility to eight years after the PhD.

Assessing the impact of funding on independence requires distinguishing between two aspects, namely intellectual independence and autonomy. Intellectual independence describes a researcher's transition from supervised research to the development and pursuit of an independent research programme. Supervised research may extend from the Masters thesis through the PhD into the first or several postdoc positions, but might also end in any of these phases. It is characterised by a supervisor's influence on the formulation of research goals, selection of approaches and methods, and interpretation of results. After this phase, researchers are expected to independently perform these actions (Laudel and Gläser 2008). 
This transition from research whose main activities are supported by a supervisor to re-search that is designed and conducted independently can be understood as the transition to intellectual independence. It must be distinguished from autonomy, which means the independent discretion over resources and the use of these resources for one's own aims. In the empirical sciences, this autonomy usually comes with the opportunity to build one's own research group, which includes discretion over infrastructure, personnel, and grants.

As the interviews demonstrated, these two aspects of independence do not necessarily coincide. All interviewees from the VRG Leader and Science Chairs programmes were intellectually independent when they applied for WWTF funding, i.e. they had already initiated an independent research line. However, several of these researchers reported that the WWTF grant enabled autonomous discretion over personnel and resources, and that only with this discretion they could make autonomous decisions about their research. The following quote describes a situation of both significant freedom and a severe restriction.

And then I was very free. This was published, and the boss said he wants to keep the one topic in the lab and if $\mathrm{I}$, as a junior researcher, want to leave, then I can't take this with me. But he let me the freedom to look for something new. It was entirely up to me what it was, and this I would be allowed to take with me, at least to some extent. And that I did. From here to there I completely changed the topic. Well, it is still [the general topic] but a completely different aspect. [VRG grant]

Similarly, other researchers reported that WWTF funding provided the first opportunity to autonomously decide about their research:

[In my former] group I had quite some freedom. But if I had wanted to do for instance [a topic I took up now], they would have frowned. They would not have told me that I couldn't but they would have asked "why do you want to do that?" What sense does it make? And then, also seeing what use is it to do that in this particular group, so you probably will not get funding for it $[\ldots .$.$] . It just didn't make sense from the$ topics around me.

$$
* * *
$$

At [my former institute] I would have been independent as well. But the whole institution had a vision or some predefined aim. This entire topic [A] would not have fitted there. [Topic B] would have been very good. However, I think if you want to pursue more independent ideas without any demands from higherup, it would have been more difficult there. And the other thing is that the number of people you can employ are limited to six at the most.

This institutionally supported autonomy seems to be particularly crucial in the life sciences. It is important because it extends the community's recognition of a researcher to the recognition of the researcher's own programme.

The WWTF project grants provided not only autonomy for intellectually independent researchers but also supported moves to intellectual independence. For nine early career researchers in my sample, the WWTF project grant provided the first opportunity to build their own research group, and thus to establish an independent research line.

Yes, and then my application was successful, fortunately. Because this application, this WWTF project was for my development and for my research group absolutely essential. Really essential. The WWTF lets you apply for relatively large grants compared to most of the other funding agencies in Austria. And for me this meant that I could employ several PhD students. And I also had some project partners [...] who where involved. And this really, this was my start-up here. This was the foundation for building my first research group. (LS, Project Grant) 
This effect could be observed in all three disciplines. In most of my cases the project grant kick-started independent research. Only one researcher did start his own research group on a project grant with a self-defined topic, but did not reach the stage of full independence. By not succeeding in acquiring external funding on this topic after the WWTF project ended, he had (again) to work on topics defined by others.

Another researcher had already reached intellectual independence during his PhD phase, but had not gained autonomy after the PhD. He had to work on topics defined by others. The WWTF grant enabled him to resume his self-defined research topic and to establish it as independent research line.

\subsection{Indirect effects of grants: Increased reputation}

The indirect effects of WWTF grants on careers are more difficult to identify and to causally attribute to the specific grants. The general causal pattern underlying them consists of the symbolic or material value of the grants enhancing the grantees' reputation, which in turn improves their chances in subsequent recruitment processes. The material value of the grant - the resources provided - enable specific research and thus the production of contributions that will be recognised by the community. The attribution of these contributions to a researcher will increase their reputation. The latter applies to both the grantees and their PhD students and postdocs. Figure 3 illustrates the indirect effects of WWTF funding; it shows a cluster of well-recognised publications that were the outcome of the funded research and provided the main profile the community could attribute to the grantee.
The beneficial indirect effects for grantees' group members are illustrated by the following quote about a former group member:

He is now a postdoc in Cambridge in a really very well-known group [...]. The things he did within the WWTF project and the publications he produced were important for that. (LS, project grant)

However, these career effects could not be systematically investigated in the framework of this study.

The symbolic value of the grant directly increases the reputation of the grantee due to the competitive nature of the grant system. Recipients of grants have successfully passed a peer review, and were deemed better than all those who did not receive funding. In times of very low success rates, particularly in the case of large grants, 'winning' a grant is considered by peers as a scientific achievement in itself and thus increases the grantee's reputation even before the funded research produced any results. This particular reputation is not limited to the grantee's community but is also important in organisational contexts. The increasing dependence of universities from external funding (both for funding research and for meeting political expectations) has made universities consider researchers' abilities to 'bring in' external money an aspect of their performance in its own right.

The reputational gain that can be achieved with the material and the symbolic value of WWTF grants can improve the grantee's chances in later recruitment processes. This effect is, however, overlaid by numerous other factors including research and funding preceding and accompanying WWTF grants as well as unrelated factors such as the thematic match of applicant and position. This is why the indirect contributions of WWTF grants to career progress are difficult to assess.
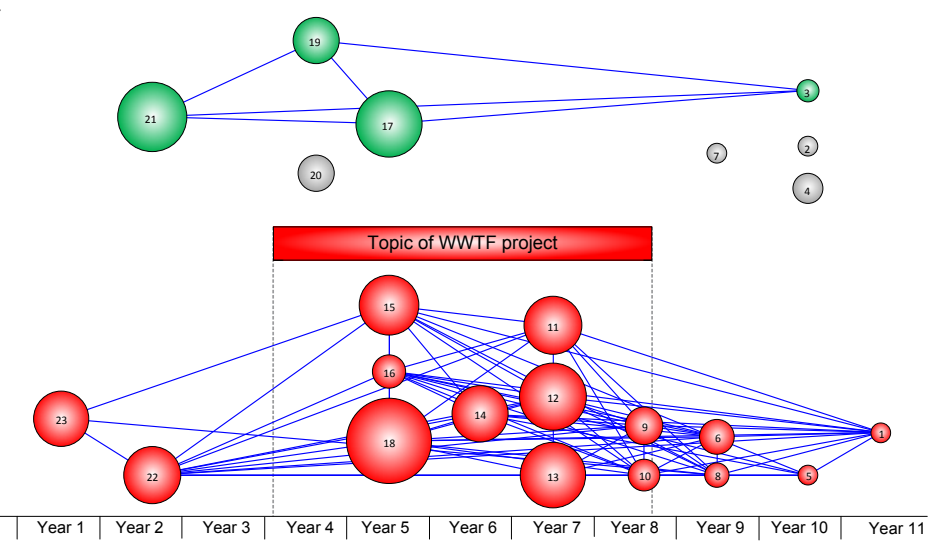


\subsection{Durability of career effects}

An important aspect of the WWTF's impact on careers is the durability of the effects. WWTF funding is awarded for a fixed term, which raises the question how lasting the changes in grantee's careers are. Answers to this question are of course always preliminary because later moves cannot be excluded. In the case of the VRG Leaders the question is meaningless because even the decisions on their tenure have not yet been made. However, some indication can be given.

Three of the four WWTF Science Chairs who finished their term were appointed to tenured professorships. One chair holder left and took a position in Switzerland. The future stay of VRG Leaders and project grant holders depends on the mix of academic and personal reasons that led to the decision for WWTF funding in the first place. The major problem is whether the levels of independence and funding achieved with the WWTF can be maintained or improved upon in the future. The WWTF and the Vienna universities have attracted excellent researchers, who of course also want to have excellent research conditions in the future, and who are likely to receive offers from other universities. For example, life scientists are likely to find the prospect of becoming an associate professor in Vienna not very attractive because they need funding for personnel, which associate professors are not entitled to.

I mean, if I get tenure then I believe they should give me something additional, a position I guess. Otherwise I will apply somewhere else. It is not at all common that you get a professorship and nothing else than your own salary.

Another important condition for interviewees was having a career perspective leading to a full professorship in due time. This was considered important not only because it extends one's own resource base but also because of the authority of the position:
One is then in a position where you can begin to influence which further professors a university recruits and so on. Just from the point of the career this is a different state where you can start to shape things more closely.

This quote clearly expresses the attitude of VRG Leaders. The WWTF intends to attract the potential elite of a research area, and these researchers naturally want to do what the elite does, namely to shape the direction of their scientific community's research both locally and globally.

The interviewed researchers who already hold tenured positions said that it is unlikely for them to leave Vienna. Apart from private reasons that become more important for older researchers, the research environment was considered as attractive:

And then I decided to stay here, for many reasons. One reason is the very good working environment that we have here. Not only what the university provides but also internally. In our institute we all work very, very closely and very well together. I have wonderful colleagues and this a value that shouldn't be underestimated. And then, of course, private reasons played a role, too. (project grant)

This can already be attributed to the interviewees' gradual shaping of their research environment during their career.

At the time of their interviews, two former project grant holders were about to leave Vienna to take up tenured positions abroad. Being in a mid-career stage, finding a tenured position was the overriding motive. At the same time, they were attracted by very good research conditions at the universities that offered the positions. A third interviewee said he is likely to go abroad because of the lack of any university funded tenure-track or tenured positions. 
The overarching aim of the WWTF is to promote the development of the Viennese research landscape. Having looked at the effects of WWTF on grantees and their research, we now want to know how (through which mechanisms and with what effects), the funding of individuals and groups affects the research landscape. This kind of impact is generally difficult to determine, and a qualitative study faces additional limitations.

While there is unanimous agreement in the science policy literature that local and regional research landscapes are important contexts for research, the empirical investigation of research landscapes, and particularly of their thematic structures, is still hampered by a lack of suitable methods. The approach of choice would be bibliometric methods, possibly combined with network analysis. However, while there are encouraging developments such as deriving google coordinates from author addresses, and mapping the disciplinary structure of research organisations, these methods are still being developed, and are not easily applied to an analysis of the Viennese research landscape.

Qualitative methods like those applied in this study can also contribute to the analysis of a research landscape but can do so only in very costly long-term analyses. As a contribution to the question asked above, this study can highlight some mechanisms through which WWTF funding contributes to shaping the Viennese research landscape, and some of the effects in the immediate environment of grantees.

\section{Achieving a fit of grantees and research landscape}

The WWTF contributes to shaping the research landscape by creating a fit of their grantees with the research that is currently conducted in Vienna. Three steps of achieving this fit are clearly identifiable. The first step is the design of the call itself. The calls identify themes that fit the landscape, and in many cases demand collaboration with other partners in Vienna.

Well, there had to be opportunities for collaboration. This was a very, very important part of the WWTF proposal indeed, to show why this special person is able to interact with 1001 people at the university. (Science Chair)

Therefore, they are likely to solicit and fund projects that have strong links to a Viennese research environment. A second step is the demand for participation and financial commitments of research organisations in two of the funding instruments, namely the Science Chair and the VRG Leader programmes. Since universities have to commit themselves to supporting the Chairs and group leaders, and to long-term investments in the fields, they will attempt to reap the greatest possible benefits from the appointments, which includes a local fit, i.e. a fit with their own research profile. The following two quotes are examples of this 'strengthening through fit' mechanism:

I found here that there was this other group doing sort of similar kind of work that was very nice. [...] there are various groups who are doing related kind of research in Vienna. There is quite a team of this and we are doing monthly seminars. Tomorrow we have one with these groups where we meet and where we talk to each other and that is I think also very special. [...] (Science Chair)

This is also the case for VRG:

I think the WWTF was very conscious that they employed somebody who would not come with a completely new thematic area but, while contributing a new aspect, does not create something completely new here. I find it far-sighted that they employ people who simply fit, strengthen the whole thing and bring in even more critical mass. (VRG leader) 
This mechanism operates both ways because already having an excellent research area attracts candidates for Science Chairs:

At this moment, this really is the best location for me in Europe, I think. Which also had to develop, of course. [...] This research focus [...] in Vienna is even stronger today than at the time when I came here. Some credit for that must be given to the WWTF. [It] was - with some additional luck - sufficient to establish an internationally visible research focus in Vienna. In [that area] it is simply the case that there is no better place in Europe. (Science Chair)

\section{Attracting further research to the funded areas}

If successful, the Science Chairs and VRG Leaders can be expected to attract further research (people and funding) to Vienna. In one case this even occurred although the former Science Chair had left Vienna before the end of his five year term. Two universities in Vienna decided to continue the Chair's research area by establishing their own chairs in this field.

And there [University A] and [University B] both said they establish a professorial position in that field and will also receive the left-over funding from the WWTF. In the meantime [University $A$ ] has completed the recruitment process. And at [University B] it is going a bit bumpy, not least because of lack of funding, not from the WWTF but from the overall university budget.

Universities also created new tenure-track positions in the research areas of two Science Chairs. How such positions can be filled depends of course on the attractiveness of the Viennese research environment. At least in some cases, the Science Chairs contributed to this attractiveness.

For example professor $X$ and professor $Y$ both came to Vienna after me. I wouldn't say it was essential that I am here but it certainly helped. The people, the famous people move where they find colleagues for whom they perhaps have some use. This is an important matter. (Science Chair)

Also at the same time someone else came not from WWTF but from other funds. A few new groups came and this established in a way also a core of [...] sciences where I think that we have actually a very nice surrounding of the field here in Vienna at hand. [Science Chair]

The WWTF grantees boosted the research in their area by attracting additional funding through external grants. They also attracted additional people who joined their groups who brought their own funding with them.

And then the person who became my first postdoc contacted me spontaneously. He knew me from scientific meetings. He said, 'hey, maybe you are looking for a postdoc'. Then we agreed that he would come, would be funded [for some time] from WWTF, and that we would apply for a fellowship, which he received. Then another postdoc came, a very good scientist who got her [...] fellowship. And then somebody else whom I knew from meetings asked me 'are you looking for postdocs'? [...] It all worked very well indeed. (VRG)

\section{Existing gaps}

On the one hand the WWTF could attract people that linked different research areas and filled gaps in its re- 
search research landscape. On the other hand, these very interdisciplinary working people also detected gaps in the Vienna research landscape of whole fields that are not present.

Q: Okay. And are there any [...biology] groups with whom you collaborate?

A: Yes. None of them is in Vienna. That's surprising, isn't it? Because Vienna has such a large [...] community. Basically they are not [... biologists] but come mostly from [a different research direction]. (Programme grant)

Some research areas exist in Vienna but are too weak to enable easily new combinations of research, combinations that exist at other places in the world under one roof.

I don't know if this is possible but a closer proximity between [field A] and [field B] would be very good for many things. We have here very strong [field $A$ ] groups and then we have 40 minutes [away] a strong [field B]. And I've been trying to go back and forth but it is different if these things are spatially closer. And there are locations where this is already the case. There is also no [field C] in Vienna. That is a bit lacking. [Programme grant]

We have seen that an important criterion of researchers to come to Vienna was the anticipated collaboration opportunities. This could again mean that an already existing research area was strengthened. But very likeIy it also meant that new research areas and expertise were brought to Vienna. Science chairs and some VRG leaders found themselves in a position where they were high in demand as collaborators, filling a gap.

There is in Vienna simply ... and there is always even more where you say, well we could, we should, let's do it. And the opportunities to collaborate are larger than what you have time for. Which is, of course, also a pleasant situation. (Science Chair)

The effects of project grants on the Vienna research landscape is more difficult to establish. Several project grants fall in the area where also Science Chairs were created. 

This empirical study provided some information about the interaction of WWTF funding with other organisations relevant for the Viennese research landscape, in particular the research organisations in Vienna and other Austrian funding organisations. Three types of relationships could be identified:

\section{'Nudging' other organisations}

The VRG Leader and the Science Chair programmes depend on the active participation of universities, which are involved in the application process and must make significant contribution in order to receive the VRG Leaders respectively Science Chairs. This means that with its temporary funding, the WWTF leverages not only matching temporary funding from the university but also permanent investment in the fields in which the WWTF funding flows.

In both programmes, applications require a "commitment" by the host organisation in form of additional resources. This commitment was substantial in the case of Science Chairs, moderate in the case of VRG grants.

And financially I had of course sufficient money so that I didn't need to write grant proposals like mad. This was really good, to be honest. [...] The [university] topped up this WWTF amount to such an extent that [for a long time] I still had funding left over. I can't complain. (Science Chair)

Q: What about equipment in the lab, where the labs already equipped?

A: Most of it was there. The situation was that we looked around what is still okay, what is not. And the university provided money. And some things were newly provided that were missing. In other cases I just took over the equipment. [...]. The equipment is okay. It could be better, of course. (VRG)

***

In the first [time] I had only the WWTF grant. The university had to top it up by 20 or 25 per cent, in the form of office space, lab space, and technical assistance. I have access to the secretarial service, to somebody who deals with the orders. [...] There is an internal budget that we get [...] But the main funding [in the first time] came from the WWTF. (VRG)

A second, more important commitment expected from universities was the creation of tenured positions. While the positions of VRG Leaders and Science Chairs are funded for a fixed term, their host universities have to provide a tenure-track position for VRG Leaders, and have to establish a chair in the fields of the Science Chairs after their term. These commitments provide the WWTF grantees with an opportunity to move to permanent professorships and to continue their research in Vienna.

This practice of the WWTF, which has already proved highly successful in the case of Science Chairs and still awaits its test for VRG Leaders, enrols research organisations in order to extend the influence of the WWTF on the Viennese research landscape far beyond its actual funding. It is, however, not without limits. The WWTF cannot influence the future resource base of its grantees. For VRG Leaders, this entails the possibility of moving from the position of a leader of a well-funded research group to the position of an Associate Professor, who has no funding for positions and little other funding. Such a prospect is particularly disheartening in the experimental fields. Science Chairs are in a similar position because the university cannot make any promises in terms of resources and personnel for the chair prior to the actual negotiations during the appointment procedure. Thus, WWTF grantees in both programmes can be confident 
about having a long-term perspective in terms of their position but face insecurity concerning their future research base.

\section{Supplementing other organisations}

The WWTF and its funding also complement efforts of other organisations, particularly funding organisations. One example was already mentioned. Several of the interviewed female recipients of project funding held FWF fellowships targeted at women (in the Hertha Firnberg or Elise Richter programmes). These fellowships provide hardly any research funding, which forces researchers to look for other sources. The WWTF grant did provide the research funding, thereby complementing the FWFs attempts to promote women by actually providing them with research opportunities.

Another, more important way of complementing other research funding organisations consisted in filling gaps in the research funding landscape. Three such gaps that were, in the opinion of interviewees, filled by the WWTF:

1. Above-average resource needs: Project grants were considered by interviewees as relatively large when compared to FWF single grants ("stand-alone projects"). This was important for early career researchers who wanted to establish a research group (for an example see page 26). Similarly, collaborative projects require a larger size because two or more research groups need funding.

2. Funding for risky research: The WWTF encourages its grantees to apply for projects that can be considered as risky, which is unusual in the Austrian funding landscape (see also 4.1). The following quotes describe three different aspects of risks, namely unexpected changes, unexplored territory, and limited guarantee of success, which were possible in all three funding programmes.
And they also give me a lot of freedom. The WWTF told me if I realise after a year that perhaps this might not be the right direction and that there is another research area that we consider as much more promising then we could also change. I think that is very flexible and very good (VRG).

What I really like about the WWTF is that they - also a bit in contrast to the FWF - have this risk-taking attitude. That they say, well, if you really want to progress then you must take into account that something goes wrong. And that is a very good idea. Because for example with the FWF you are always made small and they look that you don't get too much ... "One never knows, maybe he is totally incapable." And the WWTF says "okay, we give them a chance, we can afford it". And I think that works not so bad. (project grant)

They have a very nice side effect and this side effect is forget about today and tomorrow's research outcome but think of what is not sold, what is absolutely there is no footstep has been done in that direction. You have to think this way if you want to write a research proposal for WWTF for VRG program or for ERC. That is a good external motivation to really think out of your daily routine research. (VRG)

Several interviewees commented that this approach to risky research is markedly different from that of Austria's major funding organisation for basic research, the FWF.

A: A further difference is that the FWF is far more conservative than the WWTF.

Q: Conservative in that they want a lot of previous work? 
A: Exactly, they want previous work, security that it works. And maybe not really doing something completely different than you did before. (VRG)

3. Funding for neglected topics: In previous sections I already discussed the WWTFs approach to funding research with societal benefits and interdisciplinary research. Interviewees characterised both approaches as filling gaps in the funding landscape. With regard to societal benefits, they noted that the WWTF does not fund applied research per se but new links between basic and applied research.

When asked about funding alternatives, some researchers said they would have to split the grant into an FWF grant for the fundamental research part and a grant to the FFG (Austrian Research Promotion Agency) for the applied research part or considerably adjusting the grant for either the FWF or the FFG.

An interesting aspect of the WWTF's funding of interdisciplinary research is that the funding does not require large consortia, which is quite common nowadays. The WWTF also funds bilateral interdisciplinary collaborations and provides the funding for large projects.

The EU would have been an option but they always demand big consortia. [...] First, the call must fit the topic, and second, you need to get together a big consortium. I my view this is a research funding system as dumb as they come. [...] But the WWTF did it differently, it said "everything that plays any role in the life sciences and is of clinical relevance" - yes, it was formulated that generally back then - "can be funded". And then they look for the best ideas. And we thought this fits our topic exactly. We have something that is maybe of clinical relevance, but we don't need ten groups to investigate that, we just need two, one pre-clinical and one clinical. And therefore we were happy to apply. [LS, project grant]

\section{Being supplemented by other organisations}

The WWTF funding was used by grantees to overcome limitations of other funding organisations. Most VRG Leaders and Science Chairs considered their resources for personnel, equipment and consumables as very good, the limit of 1.5 million Euros for VRG Leader grants had different effects in different disciplines. While it was sufficient for researchers in the non-experimental science, some experimentalists needed extra resources. They found themselves in a situation where they had to apply for additional funding rather quickly (see also above, 6). 



\section{8 8. CONCLUSIONS}

All evaluations of funding programmes face the problem of identifying specific impacts underneath the general effects of money for research. Researchers are always happy when they receive funding, more money always means more research, and external funding is often used for broadening or changing individual research portfolios. Assessments based on interviews with researchers are even more challenging because researchers are likely to overemphasize positive effects and downplay negative effects. The present impact study was additionally hampered by the fact that all investigated projects and grantees received money very recently, and that some of the projects weren't even finished.

To alleviate these problems, the present study focused on the content of interviewees' research and the functions of WWTF grants for this research. This makes it possible to draw some conclusions about specific impacts of WWTF funding, which can be divided into funding specific kinds of research that might otherwise have fewer chances of finding funding, and contributions to shaping the Viennese research landscape.

Does the WWTF fund research that would otherwise be difficult to fund? Although I could base my analysis only on interviews with grantees, there are two reasons why I believe that the responses contain an important message. The first reason is that in the interviews, the grantees extensively and consistently described the properties of research they thought would be difficult to fund. From these descriptions we can derive that WWTF funding is perceived to fund risky research more easily, to fund some specific forms of interdisciplinarity, to fund some unusual interactions between basic and applied research, and to provide funding for unusually large projects. The second reason why interviewees' responses should be taken seriously is an old insight of sociology: If people believe a situation to be real, it is real in its consequences (Thomas and Thomas 1928). Applied to research funding this means that the mere belief that other funding organisations are reluctant to fund a specific kind of research can deter researchers from investing in grant proposals and pursuing this line of research. Conversely, my data showed that calls issued by the WWTF made researchers think about specific projects and specific collaborations. Thus, the WWTF provided specific targets for grant proposals, targets the applicants did not find prior to the WWTF calls. Interview responses suggest that at least some interviewees did not believe that this research could have found funding from other sources, and would not have bothered with writing a grant proposal.

How did the WWTF attract this research? The answer is easy for the unusually expensive projects because the WWTF applies an upper limit for the volume of funding that is unusually high ( 1 million Euros). In the case of risky research the WWTF apparently managed to communicate its interest through the calls and through the decision process. While this is more difficult to achieve through peer review processes, the example of the ERC already demonstrated that it is possible.

The specific forms of interdisciplinarity and of interactions between basic and applied research are more interesting because they are achieved by a specific form of calls for proposals within the WWTF's larger thematic funding programmes. The WWTF issued several calls which, while thematically still sufficiently broad, asked for particular combinations of types of fields. The most interesting examples are "Mathematics and..." and "Linking Research and Patients' Needs". With both calls, the WWTF made at least some of my interviewees think about their research in ways they have not thought about it before, or to find collaboration opportunities where prior to the calls there was only communication. The latter is likely to be also due to the emphasis on - and appropriate funding for - collaboration between groups. 
The second kind of impacts that was clearly visible in my material were changes in the Viennese research landscape. The WWTF managed to attract researchers from abroad and from Vienna whose research projects and programme fit the Viennese research landscape, strengthened it by adding to the concentration of research in certain fields, and enriched it by not merely doubling existing research but partly complementing it. With few exceptions, the people attracted to Vienna are still here and plan to stay. This high success rate, which can be confirmed even with a qualitative study due to its good coverage of the programmes in question, was achieved by very generous funding and the ways in which universities were involved. The generous funding made the positions attractive to researchers; in particular several of the VRG Leaders can be said to have had intellectual independence when they applied but to have achieved autonomy with the WWTF funding. It made the positions also interesting to universities, which are willing to engage in the selection process, to top up the WWTF funding, and to promise continuous investment in the fields of the people who were appointed. This way, the WWTF ensures very good fits of candidates with the organisational and Viennese research landscape, and is able to leverage investments in the Viennese research landscape that follows its own priorities.

Inevitably, there are some limitations to these approaches. One that hasn't manifested itself yet but was suggested in one interview is that with its search for unusual calls, the WWTF runs the risk of offering something for which there is no demand, or demanding something that researchers cannot deliver. However, the same logic that applies to research applies to research funding: Similar to researchers, research funding agencies must risk something in order to achieve something. It is not easy to see how the WWTF could achieve the same impact with a low-risk strategy.

Unfortunately, the more serious limitations to the WWTF's funding strategy appear to exist outside its control. The WWTF provides generous funding that enables interesting research but does so only for a fixed term. Several interviewees were concerned about keeping up this level of funding. The situation appears to be particularly grave for the VRG Leaders, who face the prospect of being on a permanent position but having to apply for everything else. There is little danger that former WWTF grantees move to other Austrian universities because they won't find better funding opportunities there. However, keeping the researchers the WWTF managed to attract to Vienna in Austria might turn into a problem.

Judging from the interviews with grantees, the WWTF has managed to achieve its aims by following a creative strategy that does not attempt to mirror what other major funding agencies in Austria do. It concentrates its resources in order to provide above-average funding for the few projects it can fund with its budget, and leverages more investment according to its aims. The promotion of collaboration, both interdisciplinary and between basic and applied research, was beneficial to most of the projects I investigated. While a selective funding strategy like the WWTF's is only possible for funding agencies that don't have the task of providing funding for everyone, it is still remarkable, also in international comparison. 


\section{REFERENCES}

Berezin, Alexander, 1998. The Perils of Centralized Research Funding System. Knowledge, Technology \& Policy 11: 5-26.

Chubin, Daryl E., and Edward J. Hackett, 1990. Peerless Science: Peer Review and U.S. Science Policy. Albany, N.Y.: State University of New York Press.

Edler, Jakob, 2007. Assessment of the Vienna Science and Technology Fund enowed chair program: The example of Bioinformatics. Manchester Institute of Innovation Research, Manchester Business School, University of Manchester, July 2007.

Gläser, Jochen, 2000. Limits of change: cognitive constraints on ,postmodernization" and the political redirection of science. Social Science Information 39: 439-465.

Gläser, Jochen, and Grit Laudel, 2009. Identifying individual research trails. Birger Larsen and Jacqueline Leta (eds.), Proceedings of the 12th International Society for Scientometrics and Informetrics (ISSI'09). Rio de Janeiro, 841-845.

Gläser, Jochen, and Grit Laudel, 2013. Life With and Without Coding: Two Methods for Early-Stage Data Analysis in Qualitative Research Aiming at Causal Explanations. Forum Qualitative Sozialforschung / Forum: Qualitative Social Research 14.

Heinze, Thomas, 2008. How to Sponsor Ground-Breaking Research: A Comparison of Funding Schemes. Science and Public Policy 35: 802-818.

Jonkers, Koen, 2011. Mobility, productivity, gender and career development of Argentinean life scientists. Research Evaluation 20: 411-421

Lal, Bhavya, Mary Elizabeth Hughes, Stephanie Shipp, Elizabeth Lee, C., Amy Marshall Richards, and Adrienne Zhu, 2011. Outcome Evaluation of the National Institutes of Health (NIH) Director's Pioneer Award (NDPA), FY 2004-2005. Washington: IDA Science and Technology Policy Institute.

Laudel, Grit, and Jochen Gläser, 2007. Interviewing Scientists. Science, Technology \& Innovation Studies 3: 91-111.
Laudel, Grit, and Jochen Gläser, 2008. From apprentice to colleague: the metamorphosis of Early Career Researchers. Higher Education 55: 387-406.

Laudel, Grit, and Jochen Gläser, 2012. The ERC's impact on the grantees' research and their careers (EURECIA, Work package 4 summary report). http://www.eureciaerc.net/wp-content/upLoads/EURECIA-ImpactOnResearchContentAndCareers-SummaryReport.pdf.

Luukkonen, Terttu, 2012. Conservatism and risk-taking in peer review: Emerging ERC practices. Research Evaluation 21: 48-60.

NRC (National Research Council), 2005. Bridges to Independence: Fostering the Independence of New Investigators in Biomedical Research. Washington, D.C.: The National Academies Press.

Travis, G. D. L., and H. M. Collins, 1991. New Light on Old Boys: Cognitive and Institutional Particularism in the Peer Review System. Science, Technology, \& Human Values 16: 322-341.

WWTF [Wiener Wissenschafts-, Forschungs- und Technologiefonds], 2008a. Background Paper WWTF Review Panel.

WWTF [Wiener Wissenschafts-, Forschungs- und Technologiefonds], 2008b. Enhancing WWTF's Impact on the Viennese Research Landscape - Perspectives for the next five years. Report by the International Review Panel, April 2008.

WWTF [Wiener Wissenschafts-, Forschungs- und Technologiefonds], 2010. Vienna Research Groups for Young Investigators Life Sciences, Guide for Writing a Grant Proposal. Wien: Vienna Science and Technology Fund (WWTF), January 2010.

WWTF [Wiener Wissenschafts-, Forschungs- und Technologiefonds], 2013. Supplement to the Terms of Reference for an external study in the context of the WWTF 2013 impact evaluaion, entitled "An in-depth case study of selecgted WWTF impacts"detaling the selection procedure of the case studies. WWTF, April 9, 2013. 



\section{APPENDIX}

Remark: this is the generic version of the interview guide. This guide was adapted/ specified for each interviewee.

\section{Interview Guide for Project grants}

Aim: find out how the WWTF funding influenced the research and careers of individual scientists and the Vienna research landscape.

Aim of the interview: understand your research, how it developed as well as your conditions of research

\section{Confidentiality, tape recording}

\section{Past projects}

1. Before I come to the WWTF project I would like to know how your research developed. [present picture] I would like to start with your PhD thesis which had the title ,...”. What did you want to find out with this project?

2. How did your research continue after the PhD topic-wise?

- What is the relationship to your PhD project - what remained similar, what was different?

\section{I/ Relationship to the Scientific Community}

3. If you look at the dominant topics of your SC, how is your research positioned there? are there groups who work on similar topics?
III WWTF Projekt

4. You submitted a project proposal at the WWTF ",.... Can you still remember how the idea for the project occurred?

- which role did other colleagues play in defining the topic?

5. How was the project thematically related to what you did before?

What did change?

6. To what extent did you make adjustments to the project after you had received the reviews for it?

7. How did your research continue after the WWTF project was finished?

what happened to the topic of the WWTF grant?

8. Do you need research contributions from other researchers for your research?

11. The other way around: are there research contributions that other groups need from you?

10. What did happen to the collaborations you had in the WWTF project?

IV Research conditions

11. I would like to know something about your research conditions. Time and resources are probably the most important conditions. And I would like to start with time for research. What constraints your time for research?

12. Let's have a look at resources. I have here a table. I would like to know what do you need for your research and who funds it. 
13. What would have happened with your WWTF project idea if the WWTF wouldn't have funded it?

14. You have now a considerable amount of funding. How do you intend to keep this level of funding?

$\checkmark$ Career Script

15. You came after your [previous position] here [...]. Why?

Did you have any alternatives in terms of positions?

16. You are now on a [job position]. Could you imagine to go somewhere else?

could you imagine better conditions?
VI Intentions and Plans

17. Are there any research topics that you would like to work on but can't?

Which topics? What hinders you to work on them?

18. Do you already have an idea what to research after your current project?

VII Final part

19. We talked about your research, your career and conditions of research. Is there any aspect of your research and your career that I might have forgotten ?

- $\quad$ is there anything concerning the WWTF that I should give them as a feedback (in confidential form)? 

$\mathrm{W}|\mathrm{W}| \mathrm{T} \mid \mathrm{F}$ 